\title{
Conformational Flexibility Drives Cold Adaptation in Pseudoalteromonas haloplanktis TAC125 Globins
}

\author{
Daniela Giordano, ${ }^{1,2}$ Fernando Martín Boubeta, ${ }^{3}$ Guido di Prisco, ${ }^{1}$ Dario A. Estrin, ${ }^{3}$ \\ Giulietta Smulevich, ${ }^{4}$ Cristiano Viappiani, ${ }^{5}$ and Cinzia Verde ${ }^{1,2}$
}

\begin{abstract}
Significance: Temperature is one of the most important drivers in shaping protein adaptations. Many biochemical and physiological processes are influenced by temperature. Proteins and enzymes from organisms living at low temperature are less stable in comparison to high-temperature adapted proteins. The lower stability is generally due to greater conformational flexibility.

Recent Advances: Adaptive changes in the structure of cold-adapted proteins may occur at subunit interfaces, distant from the active site, thus producing energy changes associated with conformational transitions transmitted to the active site by allosteric modulation, valid also for monomeric proteins in which tertiary structural changes may play an essential role.

Critical Issues: Despite efforts, the current experimental and computational methods still fail to produce general principles on protein evolution, since many changes are protein and species dependent. Environmental constraints or other biological cellular signals may override the ancestral information included in the structure of the protein, thus introducing inaccuracy in estimates and predictions on the evolutionary adaptations of proteins in response to cold adaptation.

Future Directions: In this review, we describe the studies and approaches used to investigate stability and flexibility in the cold-adapted globins of the Antarctic marine bacterium Pseudoalteromonas haloplanktis TAC125. In fact, future research directions will be prescient on more detailed investigation of cold-adapted proteins and the role of fluctuations between different conformational states. Antioxid. Redox Signal. 00, 000-000.
\end{abstract}

Keywords: bacterial globin, heme-pocket flexibility, hexa-coordination, oxidative/nitrosative stress, thermal adaptation

\section{General Principles}

T HE EFFECTS OF TEMPERATURE on most chemical reactions may be explained by the simple Arrhenius equation, in which the reaction rate $(k)$, typically increases with absolute temperature $(\mathrm{T})$. However, the metabolic rate of cold-adapted polar fishes living at $0^{\circ} \mathrm{C}$ is not much lower than that of species living at $40^{\circ} \mathrm{C}$, a fact that cannot be accounted for on the basis of the Arrhenius law (32). Low temperature slows down many physiological processes, reduces membrane fluidity, and increases water viscosity and gas solubility $(16,31,36,57,88)$; however, it appears that additional mechanisms of temperature compensation through natural selection and physiological plasticity are adopted for coping with low temperatures (95).

So far, relatively few cold-adapted enzymes and proteins have been structurally and functionally examined to define more general principles and depict a fully precise global and

\footnotetext{
${ }^{1}$ Institute of Biosciences and BioResources (IBBR), CNR, Napoli, Italy.

${ }^{2}$ Department of Biology and Evolution of Marine Organisms, Stazione Zoologica Anton Dohrn, Napoli, Italy.

${ }^{3}$ Departamento de Química Inorgánica, Analítica y Química Física, Facultad de Ciencias Exactas y Naturales, Universidad de Buenos Aires, Buenos Aires, Argentina.

${ }^{4}$ Department of Chemistry "Ugo Shiff," Firenze University, Firenze, Italy.

${ }^{5}$ Department of Mathematical, Physical and Computer Sciences, University of Parma, Parma, Italy.
} 
physical picture of these changes. Despite many advances in knowledge of structure-function relationship, we cannot as yet predict how many changes in the primary structure may impact the protein function and how much change is required to cope with low-temperature conditions. The presence of high levels of constitutive expression of members of HeatShock Proteins family $(10,11,47,76)$, the RNA/protein ratios $(33,34,91)$, and the high protein ubiquitination levels (87, 93) observed in several Antarctic marine species strongly support the evidence that the production of functional proteins (folded) is more challenging in polar marine species. Although cold-adapted proteins are surprisingly prone to cold denaturation, their biological activities are performed at low temperature. Therefore, in Antarctica, cold denaturation of proteins needs to be prevented to secure life. The slower capacity to produce fully functional proteins $(e . g$., limited protein supply) may probably explain the slower rates of cellular processes in polar marine species (73 and references within).

Thermodynamic stability of proteins is an important evolutionary driver in protein environmental adaptations, and some recent studies have attempted to link and quantify flexibility to adaptation to cold environments (55 and references within). Globular proteins must be stable enough to preserve their native structure and function. Thus, from a molecular biophysics perspective, protein thermodynamic stability is one of the major determinants of sequence evolution (23). Although the overall stability appears to be strongly driven by selection, proteins may explore a wide variety of mechanisms of stabilization, a phenomenon we call "thermodynamic system drift" even when selection establishes thresholds for stability (45). The lower stability in cold adaptation may be due to neutral genetic drift (random amino acid residue substitutions to decrease protein stability) for the lack of evolutionary pressure on stable enzymes in lowtemperature environments (63). However, although nature always produces cold-adapted proteins with decreased stability, indicating an inverse relationship between stability and activity, some studies have indicated that these properties are not always strictly related. Theoretical principles support the view that natural selection, rather than neutral and random drift, leads to an increase in the thermal denaturation temperature $\left(T_{m}\right)$ of proteins. The final $T_{m}$ of the protein is, in any case, the result of the balance between selection and random mutational pressure that pushes stability downward (45).

Recent models for simulating protein evolution have included the thermodynamic properties of proteins by accommodating the enthalpic (H-bonding, van der Waals interactions) and the entropic concepts (hydrophobicity, sidechain, and back-bone conformational entropy) to explain dynamics and adaptations. A growing piece of evidence suggests that thermal adaptation is associated with changes in the balance of stabilization forces $(57,92)$. In an enzymatic reaction catalyzed by cold-adapted enzymes, the decrease of the activation enthalphy $\left(\Delta \mathrm{H}^{*}\right)$ is generally the main adaptive parameter. The corresponding decrease in activation energy is achieved by decreasing the number of enthalpy-driven interactions (49). This enthalpy-entropy balance makes the rate of reactions less temperature dependent in cold-adapted enzymes, and it is believed to be the main driver in cold adaptation. The structural mechanisms behind these properties are largely unknown, being quite intricate to unravel with the current computational and experimental methods. Due to the huge number of degrees of freedom involved, the extensive sampling required to obtain $\Delta \mathrm{H}^{\mathrm{t}} \mathrm{s}$ and entropies is beyond the capacity of most quantum mechanics/molecular mechanics methods (104).

The increased protein flexibility observed in many coldadapted proteins is usually conferred by few amino-acidresidue replacements. Only minor structural modifications are generally needed to change the stability, and often local (rather than global) flexibility plays an important role in cold adaptation $(17,88,95)$.

Moreover, local unfolding confers additional potential advantages to organisms thriving in cold environments as a mechanism by regulating key enzymatic parameters such as Michaelis-Menten constant $\left(\mathrm{K}_{\mathrm{m}}\right)$ and catalytic-rate constant $\left(\mathrm{k}_{\mathrm{cat}}\right)$. In fact, the current working hypothesis is that the locally unfolded states rather than the native state may be adaptively important in driving cold adaptation. The conformational transitions are then transmitted to the active site by allosteric modulation (85).

The importance of conformational fluctuations in thermal adaptation has been known for decades, and it has been increasingly acknowledged by mutational, computational, and comparative studies on high- and low-temperature adapted proteins. Many mutational studies have highlighted the complex effects of mutations on cold-adaptation parameters $(16,18,19,32,37,54,66,94)$. These combined studies on "naturally" and laboratory-created mutants may shed light on the biological complexity of protein adaptation.

The structural/mutational approach used for experimentally testing the functional divergence of mutated proteins is challenging and may produce a detailed portrait (although sometimes controversial) of cold adaptation in proteins. In fact, due to much labor and costs, the approach often restricts analyses to a limited number of modified proteins, leading to a potentially biased view of protein adaptation.

The mutational approach was successfully used by Schrank et al. (86) and Saavedra et al. (85) to characterize Escherichia coli adenylate kinase, a small phosphotransfer enzyme in which inter-conversion between inactive (open) and active (closed) conformations is rate limiting for catalysis. The authors mutated several surface-exposed residues into Gly to demonstrate that these mutations impact the function of the protein by selectively modulating the properties of locally unfolded states/ microstates. These results are also in agreement with the evidence by Dong et al. (24), in which ligand-binding affinity properties of cytosolic malate dehydrogenase (cMDH), from 12 differently temperature adapted congeners of five molluscan genera, are affected by temperature that triggers rapid interconversion of conformational microstates (24).

This review first analyzes the challenges and the key elements of protein functioning at low temperature, with special attention to the role of flexibility. The Antarctic marine environment is challenging for the survival of microorganisms. Due to low temperature, the reduced thermal energy and the increased viscosity of water slow down all reaction rates and have an impact on dynamics and flexibility of proteins. The review then focuses on the structural and functional properties of two hemoglobins (Hbs) isolated from the Antarctic bacterium Pseudoalteromonas haloplanktis TAC125 (PhTAC125). These globins have been deeply characterized in the past decade by spectroscopic, bioinformatics, biochemical, and 
structural approaches $(41-43,48,84)$. The adaptation features inferred from the comparison of their properties with mesophilic and thermophilic counterparts are discussed with the aim of underlining some general trends in cold-adaptation strategies.

\section{Catalytic Efficiency and Thermodynamic Parameters of Cold-Adapted Proteins}

Cold-adapted proteins perform their function at low temperatures. This represents a strong physicochemical challenge, since it is known that chemical rates significantly decrease at low temperature. Some of the strategies developed at the protein level include the increasing of enzyme concentration, seasonal expression of isoenzymes, and the development of enzymes for which reaction rates tend to become temperature independent (88). The general framework to understand the effect of the temperature on chemical rates is provided by the transition-state (TS) theory (58). Most of the investigated cold-adapted enzymes evolved to achieve lower activation free energy $\left(\Delta \mathrm{G}^{*}\right) . \Delta \mathrm{G}^{*}$ is related to the $\Delta \mathrm{H}^{*}$ and activation entropy $\left(\Delta \mathrm{S}^{\dagger}\right)$, (Eq. 1$)$ :

$$
\Delta G^{\ddagger}=\Delta H^{\ddagger}-T \Delta S^{\ddagger}
$$

$\Delta \mathrm{G}^{\dagger}$ can be related to the experimental rate constant by using Eyring's equation (Eq. 2):

$$
k=\kappa \frac{k_{B} T}{h} e^{-\frac{\Delta G \dagger}{R T}}
$$

where $k$ is the reaction rate, $\kappa$ is a transmission coefficient, $k_{\mathrm{B}}$ and $h$ are the Boltzmann and Planck constants, respectively, $\mathrm{T}$ is the absolute temperature in Kelvin, and $R$ is the gas constant. From Equations 1 to 2, it can be seen that decreases in the $\Delta \mathrm{H}^{\star}$ and/or increases in $\Delta \mathrm{S}^{\dagger}$ will effectively decrease the value of $\Delta \mathrm{G}^{\dagger}$, thus increasing the chemical rate constant. The decrease in $\Delta \mathrm{H}^{*}$ is favored in cold-adapted proteins by improving the stabilizing interactions during the TS formation, thus supporting lower values of $\Delta G^{\dot{t}}$. The significantly lower values of the activation energy explain the higher specific activity of cold-adapted enzymes, although generally the observed activation energy is never as low as it would be expected due to the antagonistic effect of the activation entropy $(36,57)$.

On the other hand, an increase in $\Delta \mathrm{S}^{*}$ is necessary for decreasing $\Delta \mathrm{G}^{*}$, as enthalpy and entropy have opposite effects on $\Delta \mathrm{G}^{*}$. Since $\Delta \mathrm{S}^{*}$ values include contributions from the redistribution of water molecules, they can have negative or positive values depending on the reaction. The lower $\Delta \mathrm{S}^{*}$ values of cold-adapted enzymes compared with nonadapted homologues, observed in several reported cases, may be related to the increased flexibility of the cold-adapted proteins $(36,88)$, suggesting that their initial conformation is highly disordered compared with their temperate counterparts. Thus, the perfect cold-adapted enzyme would exhibit a decrease in the enthalpy change and/or an increase in the entropy change for the TS of the reaction. As mentioned earlier, in a psychrophilic enzyme, $\Delta S^{\dagger}$ is usually lower than that for its mesophilic counterpart, due to a more disordered ground state. For this reason, a decrease in the $\Delta \mathrm{H}^{*}$ can be considered as the main adaptive feature $(29,36,57,88)$.
Temperature has a dramatic effect, mainly due to the exponential term related to the activation free energy, but it exerts influence also on the transmission coefficient, which decreases with the increasing viscosity of low-temperature environments (35), resulting in deviations from the simple Kramers law for ligand binding kinetics $(1,2)$ and bringing to a further decrease of $\mathrm{k}_{\text {cat }}(88)$. The catalytic constant $\mathrm{k}_{\text {cat }}$ indicates the maximum number of substrate molecules converted to product per active site as a function of time; $\mathrm{k}_{\text {cat }}$ is a good index of enzyme flexibility, as it reflects the rate of transition between all conformational states involved in the catalysis. Enzymes of psychrophilic organisms are able to afford metabolic rates comparable to those of mesophilic organisms by an increase in $\mathrm{k}_{\mathrm{cat}}$. On the other hand, $\mathrm{K}_{\mathrm{m}}$ can either decrease or increase. The trade-off between $\mathrm{k}_{\text {cat }}$ and $\mathrm{K}_{\mathrm{m}}$ in cold-adapted enzymes has been comprehensively reviewed (29). Despite this, cold-adapted enzymes have high specific activities at low temperatures, often up to an order of magnitude higher than those observed in their mesophilic counterparts $(31,36,83)$. These values reflect the weak stability of these enzymes prone to inactivation and unfolding at high/moderate temperatures. Results from the analysis of some cold-adapted enzymes show that just the evaluation of $\mathrm{k}_{\mathrm{cat}}$ may be not conclusive when considering protein adaptation, and other issues, such as ligand or protein concentration and expression, may also play a crucial role (32).

Fields and co-authors (32) performed a series of studies by using two structurally and catalytically related enzymes, A4lactate dehydrogenase and $\mathrm{cMDH}$, demonstrating that ligand affinity decreases in cold adaptation to allow more rapid catalysis. However, their bioinformatic approaches failed to fully predict how a particular change of amino-acid residues alters ligand binding and catalytic rate through modifications of flexibility in localized protein areas (32). Recently, an interdisciplinary approach, combining comparative genomics, mutagenesis, kinetic analysis, and molecular modeling, highlights the importance of a very small fraction of residues as the key in enhancing catalytic activity at cold temperatures (54).

Remarkably, the activity of a cold-adapted protein at its optimal temperature is usually lower than the thermophilic or mesophilic analogous at its optimal temperature (88), thus prompting the concept of incomplete adaptations, as illustrated in many studies at the protein and species level (73). There are limits to adaptation dictated by the low temperature. These concepts also apply at the protein level, since cold-adapted enzymes often display their optimum at room temperature, thus suggesting that the evolutionary pressure pushed on the effective rate at the low working temperature, rather than shifting the rate optimum to low temperatures.

\section{Properties of Cold-Adapted Proteins}

Cold-adapted proteins are typically associated with low stability, probably due to the enhanced plasticity required to perform their function at low temperatures. Many enzymes show an increase in the flexibility of their structure to overcome low-temperature effects. It was shown that in some cases, the regions with enhanced flexibility coincide with the whole protein, whereas in others only crucial zones impact the protein flexibility (17). The role of protein dynamics, given by conformational fluctuations, has been recognized to play a key role in protein function (46). The active sites of 
many cold-adapted proteins have been found to be very similar in the static X-ray structures to those corresponding to mesophilic homologues $(28,30)$. The measurement of flexibility is challenging, since the static (the number of different conformations) as well as the dynamic flexibility (the switch between different conformations) are equally important in driving cold adaptation. In this context, structural adaptations outside the active site modify the protein dynamics, thus modulating the catalytic properties. In the tetrameric Hbs of Antarctic fish, regions such as the $\mathrm{CD} \alpha$ corner and the $\mathrm{EF} \alpha$ pocket, usually well ordered in the tense state of other tetrameric Hbs, display higher flexibility, leading to unusual distances between the heme iron and the proximal and distal His residues. In these Hbs, a significant destabilization of the tense state due to the presence of the inter-aspartic $\mathrm{H}$-bond is able to regulate the functional properties by greatly decreasing the affinity for $\mathrm{O}_{2}$ at low $\mathrm{pH}$ values (96).

The choice of residues, according to their usage in nature, is essential in the evolutionary adaptation to temperature. In bacterial enzymes, Ser, Asp, Thr, and Ala increase in the coil regions of secondary structures; whereas in the helical regions, aliphatic, basic, aromatic, and hydrophilic residues are generally under-represented $(9,16,60,80,82,83)$. In some cases, the number of Pro and Arg is reduced, whereas clusters of Gly are found, providing localized chain mobility. Moreover, reduction of surface, inter-domain, and inter-subunit ionic linkages and decreased number of H-bonds and salt bridges accompanied by an increase of number and length of loops are key mechanisms to promote increased conformational flexibility of psychrophilic enzymes $(17,30)$.

Cold-adapted proteins may possess large cavities to accommodate water molecules and/or ligands $(42,71)$ and regulate the ligand exchange between the exterior and the interior of the protein. For instance, Paredes et al. (71), comparing 20 homologous enzyme pairs from psychrophiles and mesophiles, found that psychrophilic enzymes have larger average cavity sizes, large enough for water molecules and lined with residues with acidic side chains, suggesting that embedded water molecules may play a significant role in cavity flexibility in a cold environment. In cold-adapted proteins, flexibility plays a key role also in facilitating the movement of water molecules. However, these general rules are not always valid, and each protein family may exhibit other strategies for structural adaptation. In many cases, no connection between enhanced flexibility and low thermal stability has been found or recorded with the current biochemical and spectroscopic analyses (57).

The main outcome emerging from recent studies is that there is no universal mechanism for protein adaptation to low temperature, but rather a combination of different factors, which frequently are dependent on the protein. In addition, due to the lack of general optimized methods of investigation, the results are often controversial; thus, only some general trends may be defined (79).

\section{The Case Study: The Cold-Adapted Bacterial Hbs in PhTAC125}

Comparative genome analysis indicates that a coldadapted lifestyle is generally conferred by a collection of changes in the overall genome content and composition. Challenges to cellular function and structural integrity in- clude low rates of transcription, translation and cell division, inappropriate protein folding and cold denaturation, as well as intracellular ice formation (17). Another important challenge is to cope with increased $\mathrm{O}_{2}$ solubility at low temperatures that significantly increases the production rate of reactive oxygen species (ROS). Therefore, cold-adapted organisms have developed enhanced antioxidant capacity due to the presence of multiple genes that encode catalases and superoxide dismutases.

In silico analysis of the Antarctic bacterium PhTAC125 genome shows that this cold-adapted marine bacterium may withstand the high $\mathrm{O}_{2}$ solubility by multiplying $\mathrm{O}_{2-}$ scavenging enzymes (such as dioxygenases) and removing entire metabolic pathways that produce ROS as side products. Moreover, the presence of many enzymes involved in scavenging chemical groups affected by ROS (such as peroxiredoxins and peroxidases), and one catalase-encoding gene and a possible homologue (PSHAa1737) makes the bacterium resistant to $\mathrm{H}_{2} \mathrm{O}_{2}(59)$. The presence of multiple globin genes, encoding the two-on-two $(2 / 2) \mathrm{Hbs}$, also named truncated $\mathrm{Hbs}$ (TrHbs) and a flavoHb (FHb), in distinct positions on chromosome I of PhTAC125 (41) may be an additional tool for protection against ROS and reactive nitrogen species (RNS). Although $\mathrm{FHb}$ is widely recognized to be involved in the protection against NO toxicity (77), the role of TrHbs remains poorly defined. A variety of functions have been proposed for TrHbs, including protection from ROS and RNS species, $\mathrm{O}_{2}$ and $\mathrm{NO}$ detoxification, and sulfide, nitrite, and peroxynitrite chemistry $(74,78)$. Bacterial TrHbs are characterized by a $2 / 2 \alpha$-helical-sandwich motif $(100,103)$ and, based on phylogenetic analysis, are divided into three distinct groups: $\mathrm{HbI}$ (or $\mathrm{N}$ ), $\mathrm{HbII}$ (or $\mathrm{O}$ ), and $\mathrm{HbIII}$ (or $\mathrm{P}$ ); recently, a novel, small group named HbIV (or Q) containing only bacterial sequences has been added (7). Genome analyses $(7,100)$ highlight the preponderance of two-on-two hemoglobins $(2 / 2 \mathrm{Hbs})$ in cyanobacteria and green algae. Hypotheses on the evolution of globins, as well as on the development of functional specializations, have always been proposed and debated $(98,99)$. As globins are found in all kingdoms of life, the ancestor of all globins was present in the first organisms populating the Earth. The putative original role for these proteins could have been that of detoxification after the increase of $\mathrm{O}_{2}$ levels and the evolution of photosynthesis.

PhTAC125 is one of the few examples of coexistence of genes encoding an FHb (PSHAa2880) and three TrHbs (annotated as PSHAa0030, PSHAa0458, and PSHAa2217) (42). These TrHbs in PhTAC125, being constitutively transcribed, may not be functionally redundant in their physiological function. As demonstrated in vivo, the inactivation of the gene PSHAa0030 makes the mutant bacterial strain susceptible to high $\mathrm{O}_{2}$ levels, hydrogen peroxide, and nitrosating agents (72). In addition, since the transcription of the FHbencoding gene occurs only in the mutant in which the gene PSHAa0030 was inactivated, the sensitivity to the NOinduced stress may be related to the absence of PSHAa0030 (72). Both globins, $P h-2 / 2 \mathrm{HbO}-2217$ and truncated hemoglobin encoded by PSHAa0030 gene and belonging to Pseudoalteromonas haloplanktis TAC125 [Ph-2/2HbO0030] (encoded by truncated hemoglobin encoded by PSHAa2217 gene and belonging to P. haloplanktis TAC125 [PSHAa2217] and PSHAa0030 genes, respectively), belong 
to the same group II of TrHbs and share only $24 \%$ sequence identity. These two TrHbs show typical features of group II, namely the $2 / 2 \alpha$-helical sandwich fold, a helix $\Phi$ preceding the proximal helix $\mathrm{F}$, and specific heme cavity residues in positions B10, CD1, and G8 (42).

Figure 1 shows the alignment of $P h-2 / 2 \mathrm{HbO}-2217$ and $P h-2 / 2 \mathrm{HbO}-0030$ with some representative TrHbs belonging to group II. Compared with the other TrHbs of group II, the primary structure of $P h-2 / 2 \mathrm{HbO}-0030$ and $P h-2 / 2 \mathrm{HbO}-$ 2217 includes a sequence extension at the $\mathrm{N}$ terminus, which is not involved in NO detoxification (13). Interestingly, also cold-adapted $2 / 2 \mathrm{Hb}$ of group I $(2 / 2 \mathrm{HbN})$, encoded by the PSHAa0458 gene, is endowed with an extension at the $\mathrm{N}$ terminus longer than that observed in the truncated $\mathrm{Hb}$ of group $\mathrm{N}$ of Mycobacterium tuberculosis (D. Giordano, pers. comm.); the other differences relative to the other truncated $\mathrm{Hb}$ of group $\mathrm{Os}$ (TrHbOs) are in the BC (three-residue insertion in $P h-2 / 2 \mathrm{HbO}-2217$ ), CE (one-residue deletion in $\mathrm{Ph}-2 / 2 \mathrm{HbO}-0030$ ) and $\mathrm{GH}$ (threeresidue deletion in $P h-2 / 2 \mathrm{HbO}-0030)$ loops, and in the C-terminal region (42). The heme pockets of these TrHbOs share many common features, including a number of polar cavity residues. However, the residues in positions G8 (Trp) and B10 (Tyr) are conserved in all proteins, whereas the CD1 residue is a Tyr in TrHbO of Thermobifida fusca (Tf-2/2HbO) and TrHbO of M. tuberculosis (Mt-2/2HbO),
His in the two $P h-2 / 2 \mathrm{HbO}(\mathrm{s})$, and Phe in TrHbO of Bacillus subtilis $(B s-2 / 2 \mathrm{HbO})$.

Both $P h-2 / 2 \mathrm{HbO}-2217$ and $P h-2 / 2 \mathrm{HbO}-0030$ may be involved in the protection against $\mathrm{NO}$ and related reactive species under aerobic conditions, in vivo and in vitro (12, 13). The high reactivity of $P h-2 / 2 \mathrm{HbO}-0030$ (42) and $P h-2 /$ 2HbO-2217 (12) to peroxynitrite suggests that protection against RNS and ROS is important in the cold. Low temperatures decrease nitrate uptake in bacteria, and nitrogen is fundamental for bacteria replication and protein synthesis (64).

As $P h-2 / 2 \mathrm{HbO}-2217$ and $P h-2 / 2 \mathrm{HbO}-0030$ were extensively characterized in the past decade both experimentally and computationally, their properties will be reported and discussed as examples of cold-adapted proteins showing clear signals of cold adaptation, with the aim to contribute to models for biological inference and prediction of cold adaptation.

\section{Heme pockets of cold-adapted globins}

In the canonical vertebrate myoglobin, the ferrous protein without the exogenous ligand is penta-coordinated, with an empty distal coordination site. The interaction between the heme-bound ligand and distal amino-acid residues plays a vital role in carrying out distinct redox reactions and signal triggering (4).

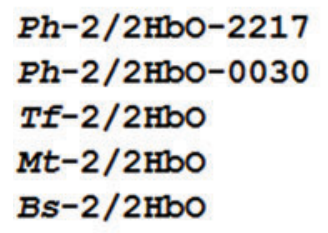

$\mathrm{Ph}-2 / 2 \mathrm{HbO}-2217$

$\mathrm{Ph}-2 / 2 \mathrm{HbO}-0030$ $T f-2 / 2 \mathrm{HbO}$ Mt $-2 / 2 \mathrm{HbO}$

$\mathrm{Ph}-2 / 2 \mathrm{HbO}-2217$

$\mathrm{Ph}-2 / 2 \mathrm{HbO}-0030$

$T f-2 / 2 \mathrm{HbO}$

Mt $-2 / 2 \mathrm{HbO}$

Bs $-2 / 2 \mathrm{HbO}$ BS $-2 / 2 \mathrm{HbO}$

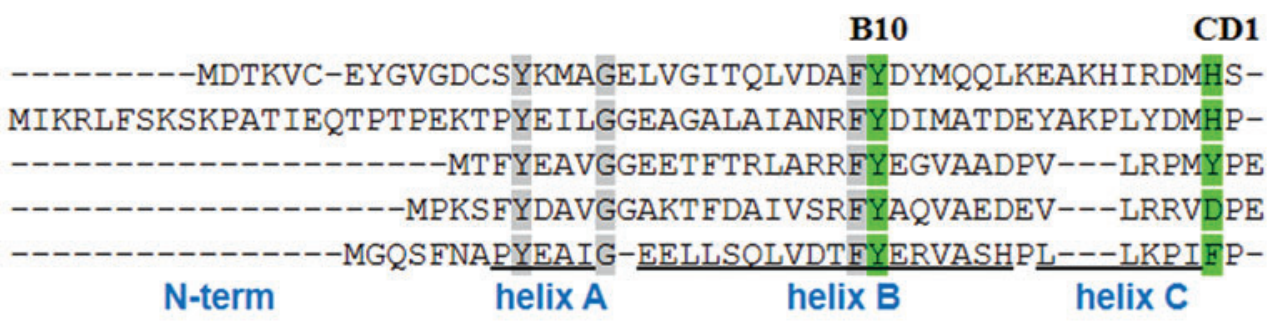

F8

G8 KDLSQSRKKLAYFLSGWMGGPKLYAEHFGS INIPQAHKHLAVGVAESEAWWLLCMQKAVDDQ LPLDRIRQVFFE FLSGWLGGPDLFVAKHGHPMLRKR HMP FT IDQDLRDQW̄MYCMNKTLDLE EDLGPAEERLRLFLMQYWGGPRTYSERRGHPRLRMR FPYRIGAEERDRWLTHMRAAVDDL DDLAGAEERLRMFLEQYWGGPRTYSEQRGHPRLRMRHAPFRISLIERDAWLLRCMHTAVAS I SDLTETARKOKOFLTOYLGGPP LYTEEHGHPMLRAR HPFPITNERADAẄLSCMKDAMDHV $\begin{array}{llll}\text { helix E } & \text { helix } \Phi & \text { helix F } & \text { helix } G\end{array}$

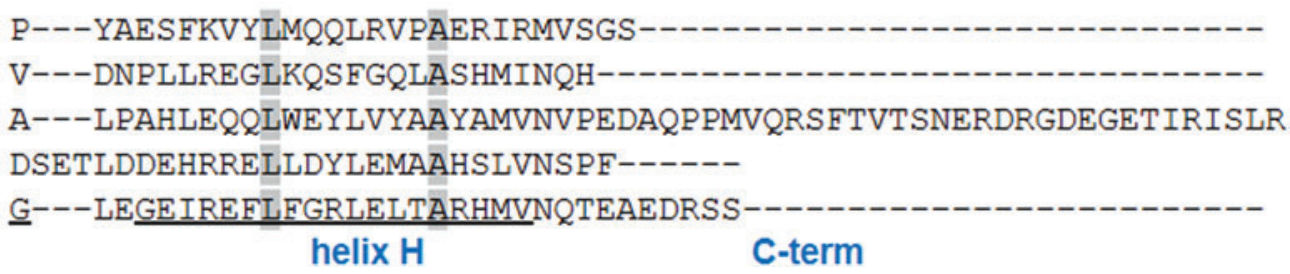

FIG. 1. Sequence alignment by Clustal Omega of Pseudoalteromonas haloplanktis $(P h-2 / 2 H b O-2217$ and Ph-2/ 2HbO-0030) compared with other members of group II, Mycobacterium tuberculosis (Mt-2/2HbO), Bacillus subtilis (Bs-2/2HbO), and Thermobifida fusca (Tf-2/2HbO). The numbering of residues is based on the position of residues in the helices of sperm whale $\mathrm{Mb}$; manual adjustments have been based on known crystal structures adapted from Giordano $e t$ al. (42). Functionally important residues (B10, CD1, and G8) specific for TrHbOs of group II are in green; HisF8, fully conserved in the globin family, in the proximal cavity, is in purple; and all other conserved residues are in gray. Helical regions A-C, E-H are indicated by underlines and helix $\Phi$, specific for $2 / 2 \mathrm{Hb}$ of group II, is shown. $B s-2 / 2 \mathrm{HbO}, \operatorname{TrHbO}$ of $B$. subtilis; $\mathrm{Hb}$, hemoglobin; $\mathrm{Mb}$, myoglobin; Mt-2/2HbO, TrHbO of M. tuberculosis; Tf-2/2HbO, TrHbO of T. fusca; TrHb, truncated $\mathrm{Hb}$; TrHbOs, truncated $\mathrm{Hb}$ of group Os. Color images are available online. 
Proteins showing coordination by a specific residue on the distal side, in either their ferric or ferrous forms, are called hexa-coordinated. Under native conditions, the Antarctic fish Hbs quantitatively form hemichrome in the $\beta$ subunits that can be reversibly converted to the classical penta-coordinated deoxy form under reduction conditions. The bis-His coordination in the ferrous state, called hemochrome, has never been observed $(97,101)$. Hemichrome detection has been suggested as a valuable tool for tumor diagnosis (14). In Antarctic fish $\mathrm{Hbs}$, although structurally and functionally analogous to mammalian $\mathrm{Hbs}$, the $\alpha$ and $\beta$ chains undergo distinct oxidation processes when exposed to air, indicating that the proteins may be involved in functional redox processes yet to be identified. The $\beta$ chains form hexacoordinated bis-His adducts, atypical in folded tetrameric Hbs, achieved through severe distortion of the heme pocket, leading to variation of the quaternary structure, which becomes intermediate between the relaxed and the tense state (101). According to their higher peroxidase activity, the exchange between two different forms, hexa-coordinated ( $\beta$ chains of ferric state) and penta-coordinated, may play a distinctive physiological role $(97,101)$.

Research over the past several years yielded a precise and complete picture of the structure of hexa-coordinated states also in neuroglobins and cytoglobins $(21,22)$. However, the physiological functions of these proteins remain elusive in vertebrates as well as in microorganisms. Although rare, endogenous hexacoordination, found in the Antarctic teleost neuroglobin (39) and cytoglobins (15), is also present in the microbial world and in the two cold-adapted globins of PhTAC125, suggesting the involvement of the globin in catalytic mechanisms of electron transfer, with the hexa-coordinated states acting as intermediates that are prone to easy reduction or oxidation $(51,52)$. From preliminary studies, $2 / 2 \mathrm{HbN}$, encoded by the PSHAa0458 gene, displays endogenous hexa-coordination (D. Giordano, pers. commun.), as it occurs in the other genes of $2 / 2 \mathrm{Hbs}$ in PhTAC125. These findings indicate the need of PhTAC125 to quickly respond to environmental challenges by implementing proteins endowed with different coordination states that function under high levels of oxidative stress.

As in other bacterial TrHbs, the heme pocket of $\mathrm{Ph}-2 /$ $2 \mathrm{HbO}-0030$ and $P h-2 / 2 \mathrm{HbO}-2217$ is very polar, with Trp, Phe, and Tyr at positions G8, B9, and B10, respectively. Moreover, in position CD1 (Figs. 1 and 2), instead of the more common Phe (7), H-bonding His is found.

The unique peculiarity of the Antarctic TrHbs is the high conformational flexibility on both the distal and proximal heme pocket cavity. In fact, although the crystal structure of $P h-2 / 2 H b O-0030$ shows that a water molecule is bound to the heme iron, in solution, resonance Raman (RR), UV-Visible, and electron paramagnetic resonance measurements show that in both ferric $P h-2 / 2 \mathrm{HbO}-0030$ and $P h-2 / 2 \mathrm{HbO}-2217$ the hexa-coordinate high-spin (6cHS) aquo form is in equilibrium with a $6 \mathrm{c}$ low spin (LS) species containing TyrB10 coordinated to the heme iron $(12,27,42)$ (Fig. 2). The 6cHS state, in equilibrium with a $6 \mathrm{cLS}$ form, is also reported in other TrHbs, namely $B s-2 / 2 \mathrm{HbO}(38), T f-2 / 2 \mathrm{HbO}(67,68)$, and $M t-2 / 2 \mathrm{HbO}$ (65); however, the nature of the LS sixth ligand is different from $\mathrm{Ph}-2 / 2 \mathrm{HbO}$, being a hydroxo complex, which becomes the only species at alkaline $\mathrm{pH}$ values.

Tyr ligation, coexisting with a $5 \mathrm{cHS}$ heme, is also present in the ferrous form of both $P h-2 / 2 \mathrm{HbO}-0030$ (43) and $P h-2 /$ 2HbO-2217 (12); however, endogenous hexa-coordination does not impair the capability of these proteins to bind diatomic ligands, in either their ferric or ferrous states, with varying thermodynamic and kinetic parameters $(51,102)$.

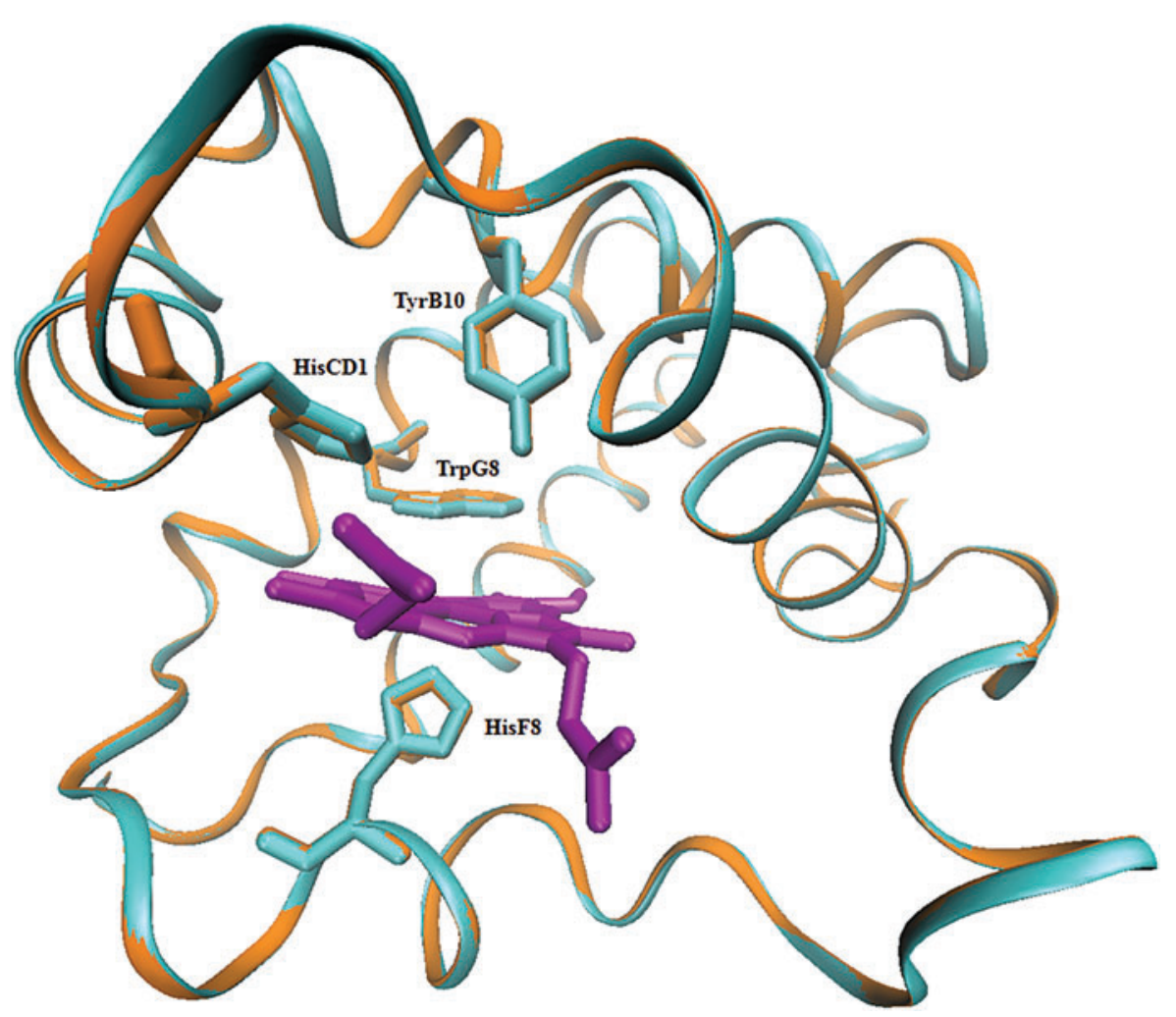

FIG. 2. Superimposition of the heme pocket of a $P h-2 / 2 \mathrm{HbO}-2217$ homology model (cyan) built by SwissModel and the $P h-2 / 2 H b O$ 0030 template structure (PDB ID 4UUR) (orange). The heme group is in purple. The residues in the heme cavity (B10, CD1, G8, F8) specific for TrHbOs of group II are shown. Adapted from Coppola et al. (12). Color images are available online. 
Although His is the most common residue that coordinates the Fe atom, Tyr coordinates the $\mathrm{Fe}$ atom of the nitrogenfixing bacterium Herbaspirillum seropedicae $\mathrm{TrHb}$ (81), which also belongs to group II and contains Trp, Phe, Tyr, and His at positions G8, B9, B10, and CD1, respectively.

The presence of a tyrosinate coordination in globins, rarely observed in other proteins, could explain the need to modulate the function $(12,42)$ by a quick adaptation to varying environmental conditions, whereas covalent modifications, as found in vertebrate monomeric globins, implying a much more stable functional signal, would require time. These coordination states may provide support for facilitating the diffusion and scavenging of $\mathrm{O}_{2}$ and/or NO. Since both $\mathrm{Ph}-2 / 2 \mathrm{HbO}-2217$ and $P h-2 / 2 \mathrm{HbO}-0030$ are involved in the protection against $\mathrm{NO}$ and related reactive species under aerobic conditions, as shown both in vivo and in vitro $(12,13)$, we cannot rule out that endogenous hexa-coordination might be a structural necessity for reversible ligand binding, essential for proteins that work under high levels of oxidative stress (51).

In the context of the proposed conformational flexibility in the cold-adapted globins, we addressed this issue also by monitoring the root mean square fluctuations (RMSF), using mesophilic $B s-2 / 2 \mathrm{HbO}$ for comparison (Fig. 3). This descriptor, frequently used in molecular dynamics (MD) simulations, measures the deviations of the motions of each particular residue with respect to its average position in the time scale of the MD simulation. As expected, the results suggest enhanced flexibility in cold-adapted $P h-2 / 2 \mathrm{HbO}-$ 0030 compared with the mesophilic analogous $B s-2 / 2 \mathrm{HbO}$. The enhanced flexibility is observed in the range of residues 30-85 associated to helices B, C, and E, and to part of the EF connecting loop (Fig. 3).

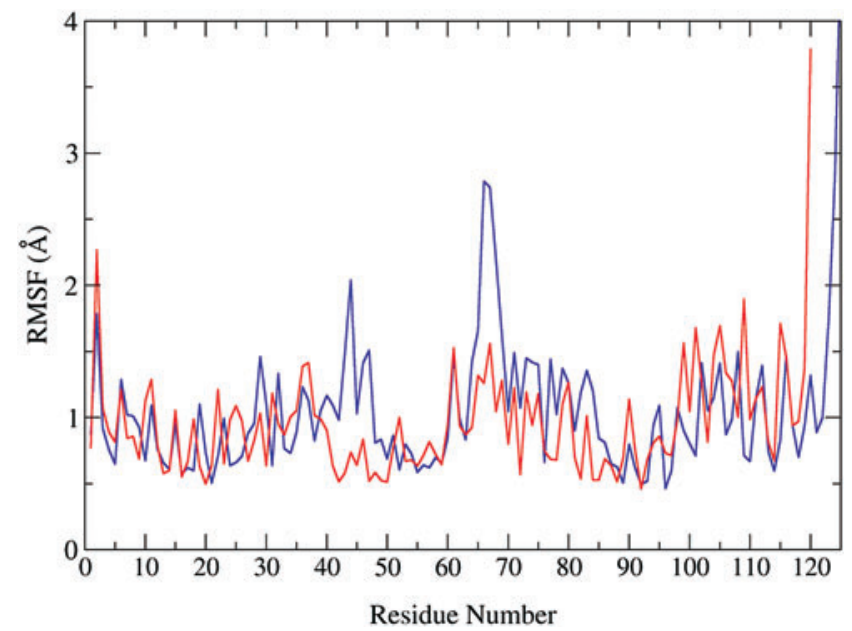

FIG. 3. RMSF obtained from three independent $100 \mathrm{~ns}$ MD simulations in $P h-2 / 2 H b O-0030$ (blue line) and $B s-2 /$ $2 \mathrm{HbO}$ (red line) at $10^{\circ} \mathrm{C}$. RMSF measure the deviations of the motions of each particular residue with respect to its average position for the time scale of the MD simulation. The regions with higher values are associated with larger dynamical fluctuations. Data on $P h-2 / 2 \mathrm{HbO}-0030$ are taken by Boubeta et al. (5), and data on $B s-2 / 2 \mathrm{HbO}$ are from $\mathrm{F}$. Boubeta (pers. comm.). Figure adapted from Boubeta et al. (5). MD, molecular dynamics; RMSF, root mean square fluctuations. Color images are available online.
RR at alkaline $\mathrm{pH}$ strongly supports also the evidence of an unusually flexible proximal heme pocket in $P h-2 / 2 \mathrm{HbO}-0030$ (42). In fact, the presence of the uncommon penta-coordinate (5c) $\mathrm{HS} \mathrm{Fe}-\mathrm{OH}^{-}$form at alkaline $\mathrm{pH}$ suggests that the proximal HisF8-Fe bond must be broken at this $\mathrm{pH}$ without denaturing the protein, since the alkaline transition is completely reversible and the protein fully restores its native state on returning to neutral $\mathrm{pH}$.

\section{Ligand-binding properties}

Cold-adapted proteins often display large internal cavities (71). Ligand binding, as well as storage and transport among these internal cavities, is responsible for small changes in the protein fluctuations that are relevant for the function. Binding of ligands may trigger transduction of signals that are allosterically transmitted to the protein (85). The interplay between protein and ligand degrees of freedom is the basis for understanding the function.

The kinetic characterization of ligand binding to group II $2 / 2 \mathrm{Hbs}$ is available for a limited number of cases, mostly with $\mathrm{CO}$ as model system, and indicates similar, but not identical, $k_{\mathrm{ON}}$ values in the CO-rebinding process, which suggest some adaptation to the environment. The importance of the distal pocket interactions for ligand binding was first proposed in $M t-2 / 2 \mathrm{HbO}$ by Guertin and coworkers (70). The MD simulations on the same protein highlighted the presence of a layer of water molecules lining the distal pocket that was suggested to impose a relevant barrier to ligand escape (50). Such findings were confirmed by Guallar et al. (44), whose results also highlighted the importance of the TrpG8 in regulating ligand migration in all TrHbOs.

Ligand-migration networks have also been suggested in detoxification mechanisms (61). Therefore, in globins, the kinetics of ligand binding are functionally important to gain insights into the structure/function relationships. Although the focus is on the physiological ligand $\mathrm{O}_{2}$, other small ligands such as $\mathrm{CO}$ may serve as alternative chemical probes. Ligand binding depends on a number of factors, including the nature and capability of the distal residues to stabilize the heme-bound ligand via $\mathrm{H}$-bonding and electrostatic interactions. The two proteins contain the same key distal polar residues; however, they share only $24 \%$ of the sequence. Interestingly, the spectroscopic data strongly indicate that $P h-2 / 2 \mathrm{HbO}-2217$ binds diatomic ligands (namely $\mathrm{CO}$ and $\mathrm{OH}^{-}$) more strongly than $P h-2 / 2 \mathrm{HbO}-0030$ (27).

Resonance Raman. RR spectroscopy has been extensively applied to the study of heme proteins (89). In fact, the Raman frequencies are sensitive to the coordination number as well as to the spin state of the iron, providing specific structural information with regard to ligation and spin state of the heme. In the study of the Antarctic TrHbOs, this technique has proved to be particularly useful, highlighting that the proteins display enhanced conformational flexibility of the heme cavity.

$\mathrm{CO}$ binding is particularly useful to investigate the nature of the distal interaction between the exogenous ligand and the residues, since the $\mathrm{CO}$ frequencies are modulated by polar interactions. In particular, the positively charged electrostatic field generated by $\mathrm{H}$-bond(s) between the $\mathrm{O}$ atom of the bound $\mathrm{CO}$ and a distal residue alters the electron distribution 
in the $\mathrm{Fe}-\mathrm{CO}$ unit, strengthening the $\mathrm{Fe}-\mathrm{C}$ bond and weakening the $\mathrm{C}=\mathrm{O}$ bond, thereby increasing the $v(\mathrm{FeC})$ vibrational frequencies and decreasing the $v(\mathrm{CO})$ frequencies. Conversely, a negatively charged electrostatic field has the opposite effect inhibiting backbonding (75). On this basis, the plot of the $v(\mathrm{FeC})$ and $v(\mathrm{CO})$ stretching frequencies for a large set of $\mathrm{CO}$ complexes, including several bacterial TrHbs, gives rise to an inverse linear correlation, where the points reflect the type and strength of distal polar interactions (25-27).

Figure 4 compares the CO complexes of $P h-2 / 2 \mathrm{HbO}-2217$ (12) and $P h-2 / 2 \mathrm{HbO}-0030$ (43) with $T f-2 / 2 \mathrm{HbO}$ (25), its triple mutant (YB10F/YCD1F/WG8F) (25), and $M t-2 / 2 \mathrm{HbO}$ (65).

$T f-2 / 2 \mathrm{HbO}$ displays two conformers, both containing a bound $\mathrm{CO}$ stabilized by polar interactions (Fig. 4) (25). MD simulation showed that in form 1 , the $\mathrm{CO}$ is stabilized by the H-bond with TrpG8; whereas in the more polar form 2, both TrpG8 and TyrCD1 are H-bonded to coordinated CO (25). The latter is the only conformer observed in $M t-2 / 2 \mathrm{HbO}(65)$, whereas $P h-2 / 2 \mathrm{HbO}-2217$ with $v(\mathrm{FeC}) / v(\mathrm{CO})$ at $506 / 1940 \mathrm{~cm}^{-1}$ is almost identical to form 1 (43). Unexpectedly, a less polar form is observed in $P h-2 / 2 \mathrm{HbO}-0030$ (12). Therefore, it appears that on $\mathrm{CO}$ binding in $\mathrm{Ph}-2 / 2 \mathrm{HbO}-0030$ a major conformational change occurs and the polar distal residues are not capable to interact with bound $\mathrm{CO}$. According to the Xray structure (42), the nonbonding lone pairs of the TyrB10 hydroxyl are oriented toward the $\mathrm{CO}$ ligand, providing negative polarity and weakening the backbonding from $\mathrm{Fe}$ to $\mathrm{CO}$. If TyrB10 moves away, the negative contribution is suppressed and a moderately positive polar environment is expected to be restored. The markedly different behavior shown by the two $P h-2 / 2 \mathrm{HbO}(\mathrm{s})$ indicates that binding is not determined exclusively by interactions with distal polar residues, but other changes in the sequence must be involved.
Axial ligand strength is a fundamental property of heme proteins, and together with the low sequence identity suggests that these proteins may play different/alternative function(s) in bacterial physiology (8).

Laser-flash photolysis. The kinetics of ligand rebinding to $P h-2 / 2 \mathrm{HbO}-0030$ after laser photolysis yielded important findings on ligand migration and binding. Ligand (CO) rebinding to Fe(II) $P h-2 / 2 \mathrm{HbO}-0030$ after laser photolysis is dominated by geminate recombination, which accounts for more than $90 \%$ of the overall rebinding reaction (5) (Fig. 5). Similarly, the amplitude of this phase is roughly $60 \%$ in $2 /$ $2 \mathrm{HbO}$ from T. fusca (red curve in Fig. 5A) (56), and 90\% in $2 /$ $2 \mathrm{HbO}$ from M. tuberculosis $(44,50)$. A substantial geminate rebinding was also observed in $B s-2 / 2 \mathrm{HbO}$, accounting for almost $50 \%$ of the overall rebinding within 2 ns from photolysis. The use of infrared probe pulses allowed to follow the spectral shift of the photodissociated $\mathrm{CO}$, which was found within a hydrophobic environment before rebinding (53).

Geminate rebinding in $P h-2 / 2 \mathrm{HbO}-0030$ (blue curve in Fig. 5A) is a multiphasic process (84) where a substantial fraction (nearly $50 \%$ of the overall reaction) occurs on the subnanosecond time scale, with an unusual extension spanning to several microseconds. The presence of multiple kinetic phases in $P h-2 / 2 \mathrm{HbO}-0030$ is evident also in the lifetime distribution reported in the blue curve in Figure 5B, where several bands appear, each of them associated with a kinetic step. In $T f-2 / 2 \mathrm{HbO}$ (red curve in Fig. 5B), multiple geminate steps are present, but a dominant process (with lifetime $\sim 2 \mathrm{~ns}$ ) accounts for most of the kinetics in this time frame. The amplitude of the sub-nanosecond phase is characterized by large variability in $2 / 2 \mathrm{HbOs}$, with values spanning from about $40 \%$ in T. fusca (red curve in Fig. 5A) to $95 \%$ in M. tuberculosis (50).

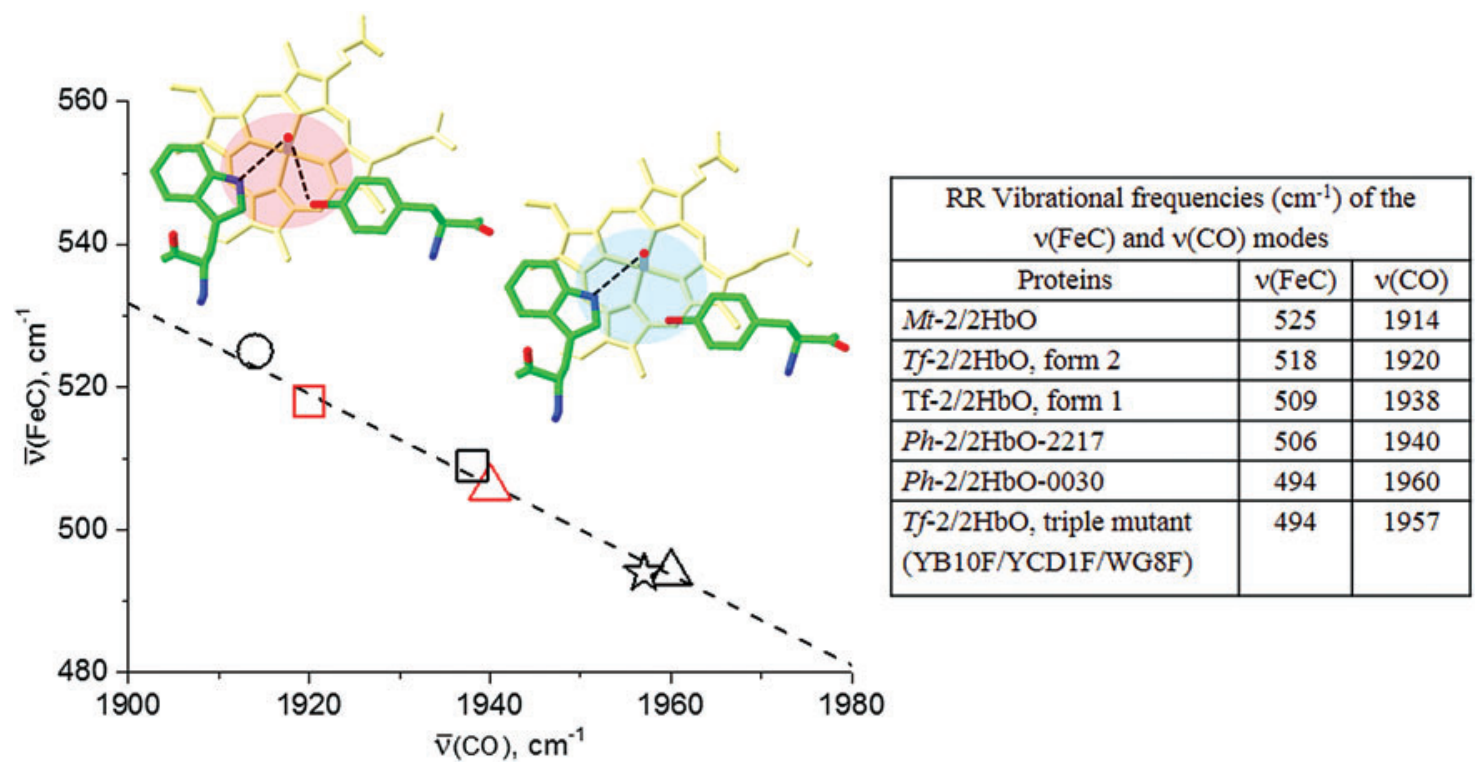

FIG. 4. Correlation plot between the $v(\mathrm{FeC})$ and $v(\mathrm{CO})$ frequencies of the two conformers of $T f-2 / 2 \mathrm{HbO}$ (form 1 [black square], and form 2 [red square]), its YB10F/YCD1F/WG8F triple mutant (star), Mt-2/2HbO (circle), Ph-2/ 2HbO-0030 (black triangle), and Ph-2/2HbO-2217 (red triangle). Schematic representation of the distal side of Tf-2/ $2 \mathrm{HbO}$, showing the H-bonds involving the iron-bound $\mathrm{CO}$ determined on the basis of MD simulations are also reported. Data referring to $T f-2 / 2 \mathrm{HbO}$ and its $\mathrm{YB} 10 \mathrm{~F} / \mathrm{YCD} 1 \mathrm{~F} / \mathrm{WG} 8 \mathrm{~F}$ triple mutant, $M t-2 / 2 \mathrm{HbO}, P h-2 / 2 \mathrm{HbO}-0030$, and $P h-2 / 2 \mathrm{HbO}-$ 2217 are taken from Droghetti et al. (25), Mukai et al. (65), Giordano et al. (43), and Coppola et al. (12), respectively. Figure adapted from Feis et al. (27). Color images are available online. 


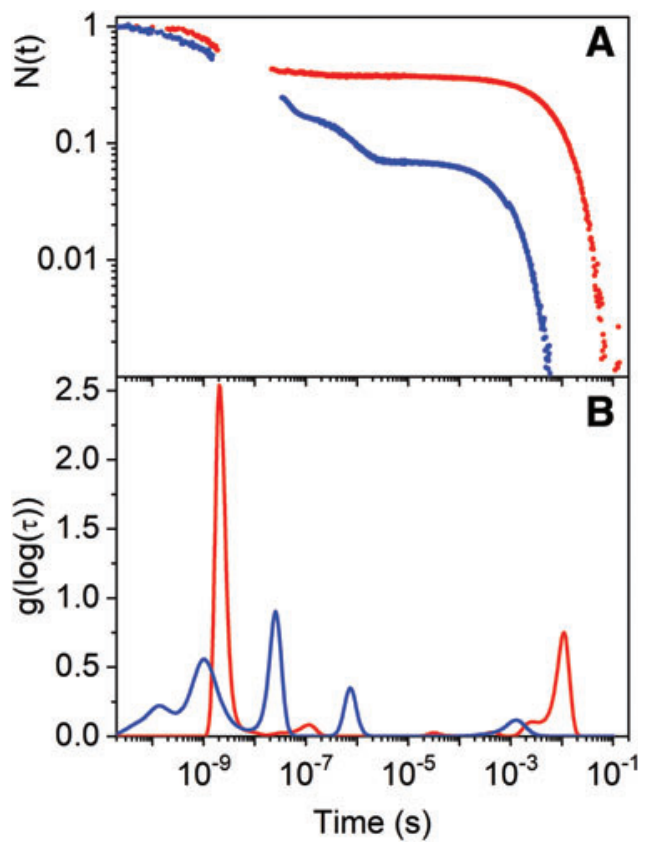

FIG. 5. Comparison between the $\mathrm{CO}$ rebinding kinetics to $P h-2 / 2 \mathrm{HbO}-0030$ (blue) and $T f-2 / 2 \mathrm{HbO}$ (red) at $\mathbf{T}=20^{\circ} \mathrm{C}$ and $\mathbf{C O}=\mathbf{1} \mathbf{a t m}$. The progress curves were obtained by merging the kinetics measured in femtosecond pump-probe experiments (from 20 ps to $\sim 2$ ns) and nanosecond laser-flash photolysis (from $\sim 30 \mathrm{~ns}$ on). (A) Progress curves for the rebinding reaction from 20 ps to $200 \mathrm{~ms}$, showing the fraction $\mathrm{N}(\mathrm{t})$ of deoxy-proteins after photolysis. In both proteins, most of the rebinding occurs geminately on sub-nanosecond time scales. In $P h-2 / 2 \mathrm{HbO}-0030$, geminate rebinding extends to the microseconds. Bimolecular rebinding is observed at longer times. (B) Lifetime distributions associated with the rebinding kinetics reported in (A) as determined by MemExp (90). Data referring to $T f-2 /$ $2 \mathrm{HbO}$ and $\mathrm{Ph}-2 / 2 \mathrm{HbO}-0030$ are taken from Marcelli et al. (56) and Boubeta et al. (5), respectively. Color images are available online.

The rebinding kinetics to $P h-2 / 2 \mathrm{HbO}-0030$ have been interpreted with a model comprising ligand migration through a structured system of cavities and tunnels that was identified by implicit ligand sampling (ILS) analysis of MD simulations (Fig. 6) (5).

Despite the high-density packing of residues in the protein core, cavities or tunnels are often present. Their presence offers an evolutionary, possibly functional, advantage to the hosting protein by providing paths or stations for the diffusion of ligands (62). In globins, as the heme is buried inside the protein matrix, ligands must migrate through thermal accessible migration pathways to reach the active site.

Figure 6A shows ILS analysis of the MD simulations on the deoxy ferrous form of $P h-2 / 2 \mathrm{HbO}-0030$, whereas Figure $6 \mathrm{~B}$ shows the kinetic scheme for the analysis of the entire $\mathrm{CO}$ rebinding kinetics.

This approach provides an estimate of the distribution of cavities formed along an MD trajectory (Fig. 6A). The results show one main tunnel connecting the solvent with an internal cavity system through which small ligands can enter and bind to the Fe atom. This hydrophobic tunnel is well described in
A
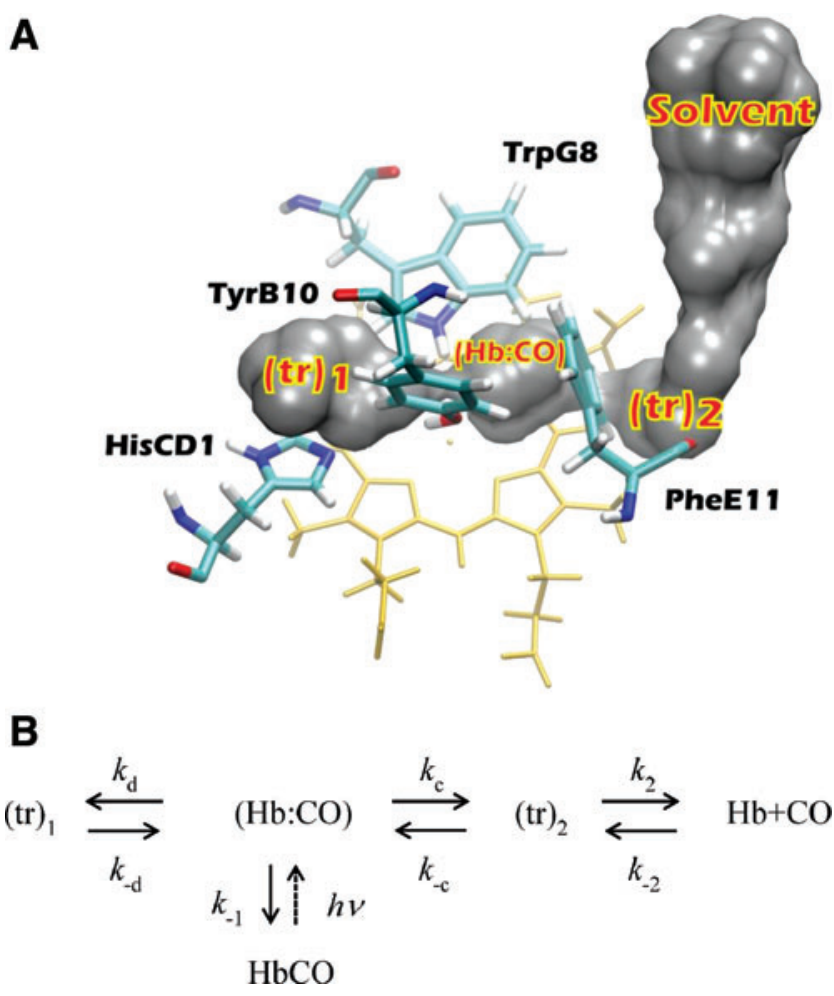

FIG. 6. The cavities and residues of the distal heme pocket of $\boldsymbol{P h - 2 / 2 H b O - 0 0 3 0 . ~ ( A ) ~ R e p r e s e n t a t i o n ~ o f ~ t h e ~}$ cavities and residues in the vicinity of the distal heme pocket of $P h-2 / 2 \mathrm{HbO}-0030$, obtained from three independent $100 \mathrm{~ns}$ MD simulations. Adapted from Boubeta et al. (5). (B) The reaction scheme proposed for $\mathrm{CO}$ rebinding to $P h-2 / 2 \mathrm{HbO}-0030$ considers the presence of cavities $(\operatorname{tr})_{1}$ and $(\operatorname{tr})_{2}$ identified by MD simulations that affect the migration kinetics inside the protein matrix between the distal cavity and the solvent phase. After photoexcitation, the photodissociated ligand is found inside the distal cavity ( $\mathrm{Hb}: \mathrm{CO}$ ), from which it can migrate either to the off-pathway cavity $(\mathrm{tr})_{1}$ or to the on-pathway cavity $(\mathrm{tr})_{2}$. From $(\mathrm{tr})_{2}$ the ligand can reach the solvent $(\mathrm{Hb}+\mathrm{CO}$ in the reaction scheme). Reaction scheme in (B) adapted from Boubeta et al. (5). Color images are available online.

other TrHbs (6). It is consistent with the RMSF analysis shown in Figure 3, in which helices B and E, involved in the channel, are the regions with larger fluctuations.

In the vicinity of the heme group, ILS and experimental results also show three docking sites, one close to the iron atom $(\mathrm{Hb}: \mathrm{CO})$ and two further away $\left[(\operatorname{tr})_{1}\right.$ and $\left.(\operatorname{tr})_{2}\right](5,42)$. In general, the distribution of the tunnels and cavities is similar to those of other TrHbs, in particular thermostable $T f-2 /$ $2 \mathrm{HbO}$. The main difference with $T f-2 / 2 \mathrm{HbO}$ is in the connectivity of the off-pathway docking site, which, in $\mathrm{Ph}-2 /$ $2 \mathrm{HbO}-0030$, is separated by different energetic barriers from the rest of the cavity system $(5,6)$.

Figure 6A also depicts three distinctive residues (TyrB10, HisCD1, TrpG8) in the active site of $P h-2 / 2 \mathrm{HbO}-0030$; the first docking site $(\operatorname{tr})_{2}$ is not impeded by any bulky residue blocking the access. In addition, the connection between $(\mathrm{Hb}: \mathrm{CO})$ and (tr) $)_{1}$ is inhibited by TrpG8 and TyrB10.

The involvement of secondary docking sites along ligand migration pathways was suggested also in $M t-2 / 2 \mathrm{HbO}$ on the 
ground of results from computer simulations. The mutation of TrpG8 in $M t-2 / 2 \mathrm{HbO}$ led to a faster geminate rebinding and the appearance of a slower kinetic phase, facts that were suggested to arise from formation of internal migration pathways, not present in the wild-type protein (44). The lack of sub-nanosecond kinetics prevents the quantitative comparison with the kinetics reported for $P h-2 / 2 \mathrm{HbO}-0030$ and $T f-2 / 2 \mathrm{HbO}$, but the overall features appear quite similar in these $2 / 2 \mathrm{HbOs}$.

Topological arrangement of cavities in $T$. fusca is quite similar to that of $P h-2 / 2 \mathrm{HbO}-0030$, but temperature dependence of the observed kinetics demonstrated different freeenergy barriers for migration between cavities in the two cases. In particular, combination of energetic barriers in $\mathrm{Ph}$ $2 / 2 \mathrm{HbO}-0030$ produces a more efficient trapping of the ligands in a temporary docking site, leading to a much slower, microsecond-lived, geminate rebinding, thus having fundamental value in the protein functioning.

In summary, these data show that availability of highresolution 3D structures may not be always sufficient to understand the functional control of ligand binding, and that the structural dynamics of the protein need to be taken into account to postulate plausible detailed mechanisms that are able to incorporate and interpret the biochemically relevant functional data.

\section{The role of water}

MD simulations on ferrous $P h-2 / 2 \mathrm{HbO}-0030$ at different temperatures $\left(10^{\circ} \mathrm{C}\right.$ and $\left.50^{\circ} \mathrm{C}\right)$ show that the active site hosts a structured H-bond network that involves TyrB10, HisCD1, TrpG8, and two water molecules (Fig. 7). MD simulations at

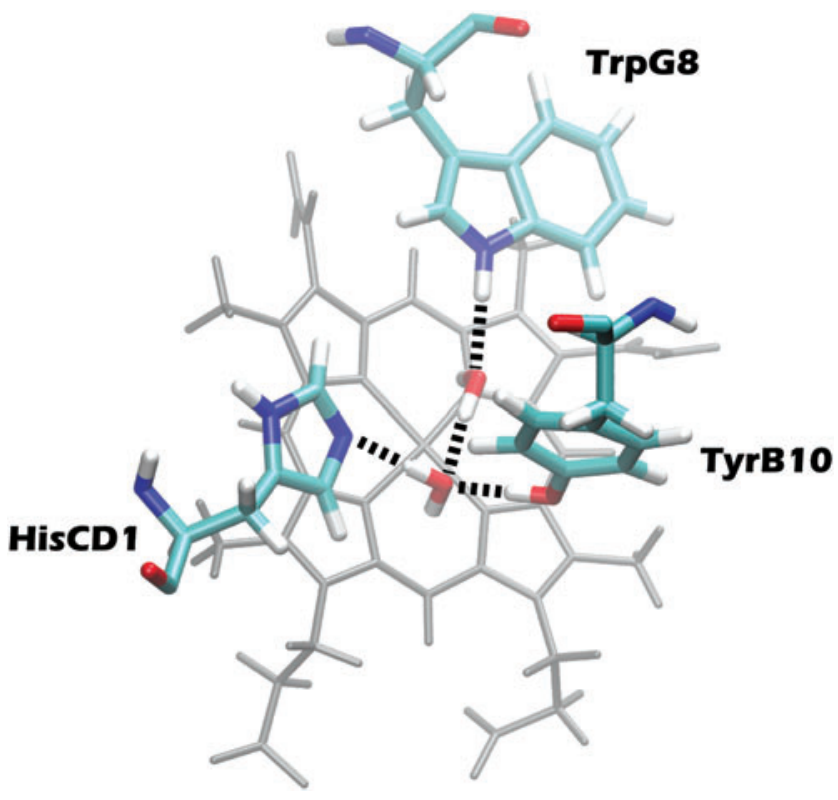

FIG. 7. Schematic representation of a typical snapshot obtained from MD simulations of ferrous $P h-2 / 2 \mathrm{HbO}$ 0030, showing two water molecules stabilized by hydrogen-bonding interactions with TyrB10, HisCD1, and TrpG8 residues. Adapted from Boubeta et al. (5). Color images are available online. low and high temperatures show that the number of H-bonds slightly decreases at high temperature, due to a more rapid exchange of water probably due to higher mobility and lower solvent viscosity at higher temperatures.

MD characterization also shows that, despite $P h-2 / 2 \mathrm{HbO}-$ 0030 and $T f-2 / 2 \mathrm{HbO}$ having similar content of water molecules, the probability (water finding probability) of finding each, and the average absolute value of the interaction energy are lower in $P h-2 / 2 \mathrm{HbO}-0030$ than in $T f-2 / 2 \mathrm{HbO}$ (5). The presence of water molecules weakly coordinated by aminoacid residues in the distal pocket of $P h-2 / 2 \mathrm{HbO}-0030$ dramatically affects the rebinding rate $\left(k_{-1}\right.$ in Fig. 5) to heme $\mathrm{Fe}(\mathrm{II})$, a parameter that directly impacts overall ligandbinding rates. Water molecules tune rebinding rates by imposing energetic barriers, as demonstrated in $T$. fusca, where mutation of residues that stabilize water molecules leads to a remarkable increase in the binding rate constant (6). In Ph-2/ $2 \mathrm{HbO}-0030$, the rate constant (and the corresponding energetic barrier) for binding is higher than in T. fusca, indicating that water stabilization is weaker and the ligand has lower barriers to overcome. Since the $\Delta \mathrm{H}^{*}$ of this process is negligible, resulting in weak or negligible temperature dependence, tuning is obtained through the entropic term (5), which in $P h-2 / 2 \mathrm{HbO}-0030$ is more favorable than in $T f-2 / 2 \mathrm{HbO}$ (56), as demonstrated in many cold-adapted enzymes. In cold-adapted proteins and enzymes, flexibility is crucial not only for securing the binding of the ligand at low temperature but also for facilitating movement of water molecules. Thermal inactivation of cold-adapted enzymes often predates the complete unfolding of the structure, thus indicating that the active site may be very sensitive to heat, even though the residues are completely conserved compared with their mesophilic/thermophilic counterparts, in which thermal inactivation generally coincide with total loss of conformation (18, 20).

As a result, the overall binding rate $k_{O N}$ for $\mathrm{CO}$ binding to $P h-2 / 2 \mathrm{HbO}-0030$ is $9.5 \times 10^{5} M^{-1} \mathrm{~s}^{-1}$ (5), much higher than the one for the dominant conformation of $T f-2 / 2 \mathrm{HbO}, k_{O N}=$ $8.7 \times 10^{4} M^{-1} \mathrm{~s}^{-1}(56)$. Interestingly, in the case of mesophilic $B s-2 / 2 \mathrm{HbO}$, ligands are rebound from the solvent with $k_{O N}=2.2 \times 10^{5} M^{-1} \mathrm{~s}^{-1}(38)$, which is an intermediate value between those of the two extremophiles. The case of $M t-2 /$ $2 \mathrm{HbO}\left(1.37 \times 10^{4} M^{-1} \mathrm{~s}^{-1}\right)$ appears to be an exception (70). Thus, $P h-2 / 2 \mathrm{HbO}-0030$ may have developed the capability of binding with a higher rate those reactive species that are further elaborated in multi-substrate reactions. This finding is in keeping with the flexibility of the distal pocket demonstrated by vibrational spectroscopy and MD simulations, and it may be interpreted as a molecular mechanism to achieve cold adaptation. Similar behaviors have been described in vertebrate cold-adapted globins (39; D. Giordano, pers. comm.) from Antarctic fish.

The influence of water molecules on reaction rates has a more general significance in terms of adaptation of molecular processes to environmental parameters such as temperature. Solvent-molecule stability inside proteins may be exploited to achieve completely different effects on reaction rate. Water has an apparently opposite effect in TrHbO from $M$. tuberculosis, where rebinding occurs almost completely within $1 \mathrm{~ns}$. In that case, the increase in the amplitude of ultrafast geminate rebinding is correlated with a network of very stable water molecules, imposing a barrier to the exit 
of the photo-dissociated ligand from the distal pocket (50). Consequently, it is virtually impossible to photo-dissociate $M t-2 / 2 \mathrm{HbO}$ in a nanosecond photolysis experiment at room temperature (70).

\section{Conclusions and Perspectives}

The properties of all macromolecules are governed by biophysical and evolutionary laws that shape the individual fitness. The integration of the biophysical (kinetics, conformational ensembles, functional motions, interactions) and the evolutionary (population genetics, molecular evolution) characterization of proteins is producing a dramatic change in our knowledge of protein structure and sequence (3).

The interface of protein structure, biophysics, and evolution (adaptation through natural selection) is the foundation for a mechanistic understanding of protein functioning in cold environments with low kinetic energy and motions. Protein geometry, stability, flexibility, ligand-binding specificity, and dynamics are important aspects in the resulting individual molecular phenotypes, thus shedding light on the probability that an individual organism survives and reproduces. Linking protein stability and dynamics to physiological functions and then to resilience to environmental changing conditions would provide mechanistic interpretations of limits, cost and consequences to respond to climate change (73).

Despite all efforts devoted to the understanding of the cold adaptation mechanisms, the picture remains incomplete for the lack of systematic and quantitative investigations. Progress in the field of cold adaptation is still limited by the lack of fully understanding the mechanisms that underline cold adaptation. Other proteins need to be thoroughly investigated to make progress in solving the complexity of adaptations at the structural level. Often our working hypotheses derive from oversimplified models that attempt to explain the effect of temperature on the structure/function of a protein. Proteins may be subjected to environmental and biological constraints that are completely unrelated to temperature adaptation, and they may override the ancestral information included in the structure of the protein, as evidenced by some mutated enzymes that display structural unexpected adaptations, different from those observed in a natural environment.

Changes in protein flexibility may play an important role in tuning biological functions at low temperatures without altering the global structure and the active site, thus reducing the selective pressure on new genes and proteins through natural selection. However, how these changes in dynamic fluctuations and conformations are then propagated to the active site, to regulate activity and function, has not been fully addressed; the information on the transition states and transient intermediates of conformational change in the native states of proteins is still missing, because these states are short lived and not directly accessible by spectroscopy or other techniques (69).

The traditional view that proteins may only count on one aspect of absolute functional specificity/activity and one fixed structure conflicts with their marked ability to adapt and evolve new functions and structures. The comparison of the three-dimensional structure of TrHbs of group II revealed no major differences in the folds of homologous psychrophilic, mesophilic, and thermophilic proteins (42). Proteins lacking sequence similarities may still share a similar threedimensional structure.

As shown in Antarctic bacterial globins, proteins are, in general, conformationally very dynamic in response to temperature physiological constraints $(40,42)$; non-native conformations are increasingly recognized to play a major role in functional dynamics and are responsible for adaptations more than the three-dimensional structure.

The main signals of cold adaptation in Antarctic TrHbOs are due to a set of conformational and flexible features on both distal and proximal heme pocket cavity that can only be appreciated in solution and not in the three-dimensional crystal structure. The coexistence in both ferric $P h-2 / 2 \mathrm{HbO}-$ 0030 and $P h-2 / 2 \mathrm{HbO}-2217$ of two different coordination states, the 6cHS aquo form and the 6cLS species, is in keeping with the proposed conformational flexibility of these cold-adapted TrHbs $(12,42)$. This flexibility is also confirmed by RMSF and ILS methodology where larger fluctuations in helices $\mathrm{B}$ and $\mathrm{E}$ and in $\mathrm{EF}$ connecting loop have been observed.

The uncommon $5 \mathrm{c}$ ferric $\mathrm{Fe}-\mathrm{OH}^{-}$form at alkaline $\mathrm{pH}$ with the proximal HisF8-Fe bond severed, completely reversible at neutral $\mathrm{pH}$, supports the evidence of an unusually flexible proximal heme pocket in $P h-2 / 2 \mathrm{HbO}-0030$ (42).

The fact that hexa-coordination is widespread in Antarctic marine organisms suggests that conformational changes and coordination states may be useful in the presence of a high $\mathrm{O}_{2}$ concentration $(39,97,101)$, possibly acting as a tool for modulating ligand binding or redox properties in lowtemperature environments.

Although the heme pocket of the two $P h-2 / 2 \mathrm{HbO}(\mathrm{s})$ shares many common features with $T f-2 / 2 \mathrm{HbO}, B s-2 / 2 \mathrm{HbO}$, and $M t-2 / 2 \mathrm{HbO}, \mathrm{RR}$ spectroscopy reveals that differences in the distal heme cavity residues markedly affect the ligand (CO) binding capability and strength of the H-bond interactions between $\mathrm{CO}$ and the conserved distal residues. As a result, the two $P h-2 / 2 \mathrm{HbOs}$ bind $\mathrm{CO}$ in a different manner, namely $P h$ 2/2HbO-2217 interacts with diatomic ligands (namely $\mathrm{CO}$ and $\mathrm{OH}-$ ) more strongly than $P h-2 / 2 \mathrm{HbO}-0030$ (27).

The higher overall binding rate $k_{\mathrm{ON}}$ for CO binding to $P h-2 /$ 2HbO-0030 in comparison to other TrHbOs may improve the overall rate for multi-substrate reactions, and it may be interpreted as a molecular signature of cold adaptation. The energetic barriers for migration between cavities in $P h-2 / 2 \mathrm{HbO}-0030$ determined in the ligand rebinding studies support a more efficient trapping of the ligands in temporary docking sites in comparison to other $\mathrm{TrHbOs}$, leading to a much slower geminate rebinding with a very large amplitude. Computer modeling identified a peculiar system of hydrophobic cavities and tunnels that connect the distal cavity to the solvent. Distal cavity mutant studies highlighted the fundamental role of the network of $\mathrm{H}$ bonds involving TrpG8, TyrCD1, TyrB10, and structural water molecules that tune the kinetic barrier to ligand binding (6). Water molecules are found to be stabilized to a lower extent in cold-adapted $P h-2 / 2 \mathrm{HbO}-0030$, thus imposing a lower barrier to ligand binding than in $T f-\operatorname{trHbO}(5)$, and speeding up the ligand binding. Comparison with $T f$-trHbO suggests that this mechanism may be related to the cold adaptation of the protein.

Variations in physicochemical features of the marine environment may require diversified responses, which may be also reflected in appropriate modulation of gene expression. Transcriptomic and genomic studies in PhTAC125 will be 
important to identify conditions where globin-gene expression changes, thus revealing the physiological function of the $2 / 2 \mathrm{Hbs}$. Phenotypic inter- and intraspecies differences are more commonly due to differences in gene expression and protein synthesis than to differences in protein structure. Moreover, the knowledge of the function of these proteins taking place in living cells under physiological conditions, rather than in vitro, would more realistically close the gap that exists between in vivo and in vitro studies.

\section{Acknowledgments}

C.V. wishes to thank Valentina Brasiello and Francesca Segreti for support and assistance and Barry Howes for helpful discussion.

\section{Funding Information}

This study was financially supported by the Italian National Programme for Antarctic Research (PNRA) (2016/ AZ1.06-Project PNRA16_00043 and 2016/AZ1.20-Project PNRA16_00128). It was carried out in the framework of the SCAR Programme "Antarctic Thresholds-Ecosystem Resilience and Adaptation" (AnT-ERA). This research was also supported in part by grants from the University of Buenos Aires (UBACYT 20020130100097BA) and ANPCYT (PICT 2014-1022, and PICT 2015-2761). The simulations have been performed in CECAR (High Performing Computing Center of the School of Sciences). C.V. acknowledges Fondazione di Piacenza e Vigevano for financial support.

\section{References}

1. Abbruzzetti S, Spyrakis F, Bidon-Chanal A, Luque FJ, and Viappiani C. Ligand migration through hemeprotein cavities: insights from laser flash photolysis and molecular dynamics simulations. Phys Chem Chem Phys 15: 1068610701, 2013

2. Ansari A, Jones CM, Henry ER, Hofrichter J, and Eaton $\mathrm{W}$. The role of solvent viscosity in the dynamics of protein conformational changes. Science 256: 1796-1798, 1992.

3. Bastolla U, Dehouck Y, and Echave J. What evolution tells us about protein physics, and protein physics tells us about evolution. Curr Opin Struct Biol 42: 59-66, 2017.

4. Bonaventura C, Henkens R, Alayash AI, Banerjee S, and Crumbliss AL. Molecular controls of the oxygenation and redox reactions of hemoglobin. Antioxid Redox Signal 18: 2298-2313, 2013.

5. Boubeta FM, Boechi L, Estrin D, Patrizi B, Di Donato M, Iagatti A, Giordano D, Verde C, Bruno S, Abbruzzetti S, and Viappiani C. Cold-adaptation signatures in the ligand rebinding kinetics to the truncated hemoglobin of the Antarctic bacterium Pseudoalteromonas haloplanktis TAC125. J Phys Chem B 122: 11649-11661, 2018.

6. Bustamante JP, Abbruzzetti S, Marcelli A, Gauto D, Boechi L, Bonamore A, Boffi A, Bruno S, Feis A, Foggi $\mathrm{P}$, Estrin DA, and Viappiani C. Ligand uptake modulation by internal water molecules and hydrophobic cavities in hemoglobins. J Phys Chem B 118: 1234-1245, 2014.

7. Bustamante JP, Radusky L, Boechi L, Estrin DA, Have AT, and Marti MA. Evolutionary and functional relationships in the truncated hemoglobin family. PLoS Comp Biol 12: e1004701, 2016.
8. Capece L, Boechi L, Perissinotti LL, Arroyo-Mañez P, Bikiel DE, Smulevich G, Marti MA, and Estrin DA. Small ligand-globin interactions: reviewing lessons derived from computer simulation. Biochim Biophys Acta 1834: 1722-1738, 2013.

9. Cavicchioli R, Siddiqui K, Andrews D, and Sowers KR. Low temperature extremophiles and their applications. Curr Opin Biotechnol 13: 253-261, 2002.

10. Clark MS, Fraser KPP, Burns G, and Peck LS. The HSP70 heat shock response in the Antarctic fish Harpagifer antarcticus. Polar Biol 31: 171-180, 2008.

11. Clark MS and Peck LS. HSP70 heat shock proteins and environmental stress in Antarctic marine organisms: a mini-review. Mar Genomics 2: 11-18, 2009.

12. Coppola D, Giordano D, Milazzo L, Howes BD, Ascenzi P, di Prisco G, Smulevich G, Poole RK, and Verde C. Coexistence of multiple globin genes conferring protection against nitrosative stress to the Antarctic bacterium Pseudoalteromonas haloplanktis TAC125. Nitric Oxide 73: 39-51, 2018.

13. Coppola D, Giordano D, Tinajero-Trejo M, di Prisco G, Ascenzi P, Poole RK, and Verde C. Antarctic bacterial hemoglobin and its role in the protection against nitrogen reactive species. Biochim Biophys Acta 1834: 1923-1931, 2013.

14. Croci S, Pedrazzi G, Passeri G, Piccolo P, and Ortalli I. Acetylphenylhydrazine induced haemoglobin oxidation in erythrocytes studied by Mossbauer spectroscopy. Biochim Biophys Acta 1568: 99-104, 2001.

15. Cuypers B, Vermeylen S, Hammerschmid D, Trashin S, Rahemi V, Konijnenberg A, De Schutter A, Cheng C-HC, Giordano D, Verde C, De Wael JK, Sobott F, Dewilde S, and Van Doorslaer S. Antarctic fish versus human cytoglobins - the same but yet so different. J Inorg Biochem 173: 66-78, 2017.

16. D'Amico S, Claverie P, Collins T, Georlette D, Gratia E, Hoyoux A, Meuwis MA, Feller G, and Gerday C. Molecular basis of cold adaptation. Philos Trans $R$ Soc Lond B Biol Sci 357: 917-925, 2002.

17. D'Amico S, Collins T, Marx JC, Feller G, and Gerday C. Psychrophilic microorganisms: challenges for life. EMBO Rep 7: 385-389, 2006.

18. D'Amico S, Gerday C, and Feller G. Structural determinants of cold adaptation and stability in a large protein. $J$ Biol Chem 276: 25791-25796, 2001.

19. D'Amico S, Gerday C, and Feller G. Dual effects of an extradisulfide bond on the activity and stability of a coldadapted $\alpha$-amylase. J Biol Chem 277: 46110-46115, 2002.

20. D'Amico S, Marx JC, Gerday C, and Feller G. Activity stability relationships in extremophilic enzymes. $J$ Biol Chem 278: 7891-7896, 2003.

21. Dewilde S, Kiger L, Burmester T, Hankeln T, BaudinCreuza V, Aerts T, Marden MC, Caubergs R, and Moens L. Biochemical characterization and ligand binding properties of neuroglobin, anovel member of the globin family. J Biol Chem 276: 38949-38955, 2001.

22. de Sanctis D, Dewilde S, Pesce A, Moens L, Ascenzi P, Hankeln T, Burmester T, and Bolognesi M. Crystal structure of cytoglobin: the fourth globin type discovered in man displays heme hexa-coordination. J Mol Biol 336: 917-927, 2004.

23. Dokholyan NV and Shakhnovich EI. Understanding hierarchical protein evolution from first principles. $J \mathrm{Mol}$ Biol 312: 289-307, 2001. 
24. Dong Y-W, Liao M-L, Meng X-L, and Somero GN. Structural flexibility and protein adaptation to temperature: molecular dynamics analysis of malate dehydrogenases of marine molluscs. Proc Natl Acad Sci U S A 115: 1274-1279, 2018.

25. Droghetti E, Nicoletti FP, Bonamore A, Boechi L, Manez PA, Estrin DA, Boffi A, Smulevich G, and Feis A. Heme pocket structural properties of a bacterial truncated hemoglobin from Thermobifida fusca. Biochemistry 49: 10394-10402, 2010.

26. Egawa T and Yeh SR. Structural and functional properties of hemoglobins from unicellular organisms as revealed by resonance Raman spectroscopy. J Inorg Biochem 99: 7296, 2005.

27. Feis A, Howes BD, Milazzo L, Coppola D, and Smulevich G. Structural determinants of ligand binding in truncated hemoglobins: resonance Raman spectroscopy of the native states and their carbon monoxide and hydroxide complexes. Biopolymers 109: e23114, 2018.

28. Feller G. Molecular adaptations to cold in psychrophilic enzymes. Cell Mol Life Sci 60: 648-662, 2003.

29. Feller G. Psychrophilic enzymes: from folding to function and biotechnology. Scientifica 2013: 512840, 2013.

30. Feller G and Gerday C. Psychrophilic enzymes: molecular basis of cold adaptation. Cell Mol Life Sci 53: 830-841, 1997.

31. Feller G and Gerday C. Psychrophilic enzymes: hot topics in cold adaptation. Nat Rev Microbiol 1: 200-208, 2003.

32. Fields PA, Dong Y, Meng X, and Somero GN. Adaptations of protein structure and function to temperature: there is more than one way to 'skin a cat'. J Exp Biol 218: 1801-1811, 2015.

33. Fraser KPP, Clarke A, and Peck LS. Feast and famine in Antarctica: seasonal physiology in the limpet, Nacella concinna (Strebel, 1908). Mar Ecol Prog Ser 242: 169177, 2002.

34. Fraser KPP, Clarke A, and Peck LS. Growth in the slow lane: protein metabolism in the Antarctic limpet Nacella concinna (Strebel, 1908). J Exp Biol 210: 2691-2699, 2007.

35. Garcia Viloca M, Gao J, Karplus M, and Truhlar DG. How enzymes work: analysis by modern rate theory and computer simulations. Science 303: 186-195, 2004.

36. Georlette D, Blaise V, Collins T, D'Amico SD, Gratia E, Hoyoux A, Marx J-C, Sonan G, Feller G, and Gerday C. Some like it cold: biocatalysis at low temperatures. FEMS Microbiol Rev 28: 25-42, 2004.

37. Gerike U, Danson MJ, and Hough DW. Cold-active citratesynthase: mutagenesis of active-site residues. Protein Eng 14: 655-661, 2001.

38. Giangiacomo L, Ilari A, Boffi A, Morea V, and Chiancone E. The truncated oxygen-avid hemoglobin from Bacillus subtilis X-ray structure and ligand binding properties. $J$ Biol Chem 280: 9192-9202, 2005.

39. Giordano D, Boron I, Abbruzzetti S, Van Leuven W, Nicoletti FP, Forti F, Bruno S, Cheng C-HC, Moens L, di Prisco G, Nadra AD, Estrin D, Smulevich G, Dewilde S, Viappiani C, and Verde C. Biophysical characterisation of neuroglobin of the icefish, a natural knockout for hemoglobin and myoglobin. Comparison with human neuroglobin. PLoS One 7: e44508, 2012.

40. Giordano D, Coppola D, Russo R, Tinajero-Trejo M, di Prisco G, Lauro F, Ascenzi P, and Verde C. The globins of cold-adapted Pseudoalteromonas haloplanktis TAC125: from the structure to the physiological functions. $A d v$ Microb Physiol 63: 329-389, 2013.

41. Giordano D, Parrilli E, Dettaï A, Russo R, Barbiero G, Marino G, Lecointre G, di Prisco G, Tutino L, and Verde C. The truncated hemoglobins in the Antarctic psychrophilic bacterium Pseudoalteromonas haloplanktis TAC125. Gene 398: 69-77, 2007.

42. Giordano D, Pesce A, Boechi L, Bustamante JP, Caldelli E, Howes BD, Riccio A, di Prisco G, Nardini M, Estrin D, Smulevich G, Bolognesi M, and Verde C. Structural flexibility of the heme cavity in the cold-adapted truncated hemoglobin from the Antarctic marine bacterium Pseudoalteromonas haloplanktis TAC125. FEBS J 282: 29482965, 2015.

43. Giordano D, Russo R, Ciaccio C, Howes BD, di Prisco G, Marden MC, Hui Bon Hoa G, Smulevich G, Coletta M, and Verde C. Ligand- and proton-linked conformational changes of the ferrous $2 / 2$ hemoglobin of Pseudoalteromonas haloplanktis TAC125. IUBMB Life 63: 566-573, 2011.

44. Guallar V, Lu C, Borrelli K, Egawa T, and Yeh SR. Ligand migration in the truncated hemoglobin-II from $M y$ cobacterium tuberculosis: the role of G8 tryptophan. $J$ Biol Chem 284: 3106-3116, 2009.

45. Hart KM, Harms MJ, Schmidt BH, Elya C, Thornton JW, and Marqusee S. Thermodynamic system drift in protein evolution. PLoS Biol 12: e1001994, 2014.

46. Henzler-Wildman KA. A hierarchy of timescales in protein dynamics is linked to enzyme catalysis. Nature 450: 913-916, 2007.

47. Hofmann GE, Lunda SG, Placea SP, and Whitmer AC. Some like it hot, some like it cold: the heat shock response is found in New Zealand but not Antarctic notothenioid fishes. J Exp Mar Biol Ecol 316: 79-89 51, 2005.

48. Howes BD, Giordano D, Boechi L, Russo R, Mucciacciaro S, Ciaccio C, Sinibaldi F, Fittipaldi M, Martí MA, Estrin DA, di Prisco G, Coletta M, Verde C, and Smulevich G. The peculiar heme pocket of the $2 / 2$ hemoglobin of coldadapted Pseudoalteromonas haloplanktis TAC125. J Biol Inorg Chem 16: 299-311, 2011.

49. Isaksen GV, Åquist J, and Brandsdal BO. Enzyme surface rigidity tunes the temperature dependence of catalytic rates. Proc Natl Acad Sci U S A 113: 7822-7827, 2016.

50. Jasaitis A, Ouellet H, Lambry JC, Martin JL, Friedman $\mathrm{JM}$, Guertin M, and Vos MH. Ultrafast heme-ligand recombination in truncated hemoglobin $\mathrm{HbO}$ from Mycobacterium tuberculosis: a ligand cage. Chem Phys 396: 10-16, 2012.

51. Johnson EA and Lecomte JTJ. The globins of cyanobacteria and algae. Adv Microb Physiol 63: 195-272, 2013.

52. Kakar S, Hoffman FG, Storz JF, Fabian M, and Hargrove MS. Structure and reactivity of hexacoordinate hemoglobins. Biophys Chem 152: 1-14, 2010.

53. Lapini A, Di Donato M, Patrizi B, Marcelli A, Lima M, Righini R, Foggi P, Sciamanna N, and Boffi A. Carbon monoxide recombination dynamics in truncated hemoglobins studied with visible-pump mid IR-probe spectroscopy. J Phys Chem B 116: 8753-8761, 2012.

54. Laye VJ, Karan R, Kim J-M, Pecher WT, Das Sarma P, and Das Sarma S. Key amino acid residues conferring enhanced enzyme activity at cold temperatures in an Antarctic polyextremophilic $\beta$-galactosidase. Proc Natl Acad Sci U S A 114: 12530-12535, 2017. 
55. Liberles DA, Sarah A. Teichmann SA, Bahar I, Bastolla U, Bloom J, Bornberg-Bauer E, Colwell LJ, de Koning APJ, Dokholyan NV, Echave J, Elofsson A, Gerloff DL, Goldstein RA, Grahnen JA, Holder MT, Lakner C, Lartillot N, Lovell SC, Naylor G, Perica T, Pollock DD, Pupko T, Regan L, Roger A, Rubinstein N, Shakhnovich E, Sjölander K, Sunyaev S, Teufel AI, Thorne JL, Thornton JW, Weinreich DM, and Whelan S. The interface of protein structure, protein biophysics, and molecular evolution. Prot Sci 21: 769-785, 2012.

56. Marcelli A, Abbruzzetti S, BustamanteJP, Feis A, Bonamore A, Boffi A, Gellini C, Salvi PR, Estrin DA, Bruno S, Viappiani C, and Foggi P. Following ligand migration pathways from picoseconds to milliseconds in type II truncated hemoglobin from Thermobifida fusca. PLoS One 7: e39884, 2012.

57. Marx J-C, Collins T, D'Amico SD, Feller G, and Gerday C. Cold adapted enzyme from marine antarctic microorganisms. Mar Biotechnol 9: 293-304, 2007.

58. McGeagh JD, Ranaghan KE, and Mulholland AJ. Protein dynamics and enzyme catalysis: insights from simulations. Biochim Biophys Acta 1814: 1077-1092, 2011.

59. Médigue C, Krin E, Pascal G, Barbe V, Bernsel A, Bertin PN, Cheung F, Cruveiller S, D'Amico S, Duilio A, Fang G, Feller G, Ho C, Mangenot S, Marino G, Nilsson J, Parrilli E, Rocha EP, Rouy Z, Sekowska A, Tutino ML, Vallenet D, von Heijne G, and Danchin A. Coping with cold: the genome of the versatile marine Antarctica bacterium Pseudoalteromonas haloplanktis TAC125. Genome Res 15: 1325-1335, 2005.

60. Metpally RPR and Reddy BVB. Comparative proteome analysis of psychrophilic versus mesophilic bacterial species: insights into the molecular basis of cold adaptation of proteins BMC Genomics 10: 11, 2009.

61. Milani M, Pesce A, Ouellet Y, Dewilde S, Friedman J, Ascenzi P, Guertin M, and Bolognesi M. Heme-ligand tunneling in group I truncated hemoglobins. $J$ Biol Chem 279: 21520-21525, 2004.

62. Milani M, Savard PY, Ouellet H, Ascenzi P, Guertin M, and Bolognesi M. A TyrCD1/TrpG8 hydrogen bond network and a TyrB10-TyrCD1 covalent link shape the heme distal site of Mycobacterium tuberculosis hemoglobin O. Proc Natl Acad Sci U S A 100: 5766-5771, 2003.

63. Miyazaki K, Wintrode PL, Grayling RA, Rubingh DN, and Arnold FH. Directed evolution study of temperature adaptation in a psychrophilic enzyme. J Mol Biol 297: 1015-1026, 2000.

64. Moreno-Vivián C, Cabello P, Martínez-Luque M, Blasco $\mathrm{R}$, and Castillo F. Prokaryotic nitrate reduction: molecular properties and functional distinction among bacterial nitrate reductases. J Bacteriol 181: 6573-6584, 1999.

65. Mukai M, Savard PY, Ouellet H, Guertin M, and Yeh SR. Unique ligand-protein interactions in a new truncated hemoglobin from Mycobacterium tuberculosis. Biochemistry 41: 3897-3905, 2002.

66. Narinx E, Baise E, and Gerday C. Subtilisin from psychrophilic antarctic bacteria: characterization and site directed mutagenesis of residues possibly involved in the adaptation to cold. Protein Eng 10: 1271-1279, 1997.

67. Nicoletti FP, Droghetti E, Howes BD, Bustamante JP, Bonamore A, Sciamanna N, Estrin DA, Feis A, Boffi A, and Smulevich G. H-bonding networks of the distal residues and water molecules in the active site of Thermo- bifida fusca hemoglobin. Biochim Biophys Acta 1834: 1901-1909, 2013.

68. Nicoletti FP, Bustamante JP, Droghetti E, Howes BD, Fittipaldi M, Bonamore A, Baiocco P, Feis A, Boffi A, Estrin DA, and Smulevich G. Interplay of the H-bond donor-acceptor role of the distal residues in hydroxyl ligand stabilization of Thermobifida fusca truncated hemoglobin. Biochemistry 53: 8021-8030, 2014.

69. Olsson U and Wolf-Watz M. Overlap between folding and functional energy landscapes for adenylate kinase conformational change. Nat Commun 1: 111, 2010.

70. Ouellet H, Juszczak, L, Dantsker D, Samuni U, Ouellet YH, Savard PY, Wittenberg JB, Wittenberg BA, Friedman $\mathrm{JM}$, and Guertin M. Reactions of Mycobacterium tuberculosis truncated hemoglobin $\mathrm{O}$ with ligands reveal a novel ligand-inclusive hydrogen bond network. Biochemistry 42: 5764-5774, 2003.

71. Paredes DI, Watters K, Pitman DJ, Bystroff C, and Dordick JS. Comparative void-volume analysis of psychrophilic and mesophilic enzymes: structural bioinformatics of psychrophilic enzymes reveals sources of core flexibility. BMC Struct Biol 11: 42, 2011.

72. Parrilli E, Giuliani M, Giordano D, Russo R, Marino G, Verde C, and Tutino ML. The role of a 2-on-2 haemoglobin in oxidative and nitrosative stress resistance of Antarctic Pseudoalteromonas haloplanktis TAC125. Biochimie 92: 1003-1009, 2010.

73. Peck LS. A cold limit to adaptation in the sea. Trends Ecol Evol 31: 13-26, 2016.

74. Pesce A, Couture M, Dewilde S, Guertin M, Yamauchi K, Ascenzi P, Moens L, and Bolognesi M. A novel two-overtwo a-helical sandwich fold is characteristic of the truncated hemoglobin family. EMBO J 19: 2424-2434, 2000.

75. Phillips GN, Teodoro ML, Li TS, Smith B, and Olson JS. Bound $\mathrm{CO}$ is a molecular probe of electrostatic potential in the distal pocket of myoglobin. J Phys Chem B 103: 8817-8829, 1999.

76. Place SP and Hofmann GE. Constitutive expression of a stress-inducible heat shock protein gene, hsp70, in a phylogenetically distant Antarctic fish. Polar Biol 28: 261-267, 2005.

77. Poole RK. Nitric oxide and nitrosative stress tolerance in bacteria. Biochem Soc Trans 33: 176-180, 2005.

78. Poole RK and Hughes MN. New functions for the ancient globin family: bacterial responses to nitric oxide and nitrosative stress. Mol Microbiol 36: 775-783, 2000.

79. Pucci F and Rooman R. Physical and molecular bases of protein thermal stability and cold adaptation. Curr Opin Struct Biol 42: 117-128, 2017.

80. Ray MK, Kumar GS, Janiyani K, Kannan K, Jagtap P, Basu MK, and Shivaji S. Adaptation to low temperature and regulation of gene expression in Antarctic psychrotrophic bacteria. J Biosci 23: 423-435, 1998.

81. Razzera G, Vernal J, Baruh D, Serpa VI, Tavares C, Lara F, Souza EM, Pedrosa FO, Almeida FC, Terenzi H, and Valente AP. Spectroscopic characterization of a truncated hemoglobin from the nitrogen-fixing bacterium Herbaspirillum seropedicae. J Biol Inorg Chem 13: 1085-1096, 2008.

82. Rodrigues DF and Tiedje JM. Coping with our cold planet. Appl Environ Microbiol 74: 1677-1686, 2008.

83. Russell NJ. Molecular adaptations in psychrophilic bacteria: potential for biotechnological applications. $A d v$ Biochem Eng Biotechnol 61: 1-21, 1998. 
84. Russo R, Giordano D, di Prisco G, Hui Bon Hoa G, Marden MC, Verde C, and Kiger L. Ligand-rebinding kinetics of $2 / 2$ hemoglobin from the Antarctic bacterium Pseudoalteromonas haloplanktis TAC125. Biochim Biophys Acta 1834: 1932-1938, 2013.

85. Saavedra HG, Wrabl JO, Anderson JA, Li J, and Hilser VJ. Dynamic allostery can drive cold adaptation in enzymes. Nature 558: 324-328, 2018.

86. Schrank TP, Bolen DW, Vincent J, and HilserVJ. Rational modulation of conformational fluctuations inadenylate kinase reveals a local unfolding mechanism for allostery and functional adaptation in proteins. Proc Natl Acad Sci U S A 106: 16984-16989, 2009.

87. Shin SC, Kim SJ, Lee JK, Ahn DH, Kim MG, Lee H, Lee J, Kim BK, and Park H. Transcriptomics and comparative analysis of three Antarctic notothenioid fishes. PLoS One 7: e43762, 2012.

88. Siddiqui KS and Cavicchioli R. Cold-adapted enzymes. Annu Rev Biochem 75: 403-433, 2006.

89. Spiro TG and Li XY. Resonance Raman spectroscopy of metalloporphyrins. In: Biological Applications of Raman Spectroscopy, edited by Spiro TG. New York: John Wiley and sons, Inc., 1988, vol. 3, pp. 1-37.

90. Steinbach PJ, Ionescu R, and Matthews CR. Analysis of kinetics using a hybrid maximum-entropy/nonlinear-leastsquares method: application to protein folding. Biophys $J$ 82: 2244-2255, 2002.

91. Storch D, Lannig G, and Pörtner HO. Temperaturedependent protein synthesis capacities in Antarctic and temperate (North Sea) fish (Zoarcidae). J Exp Biol 208: 2409-2420, 2015.

92. Tehei M, Franzetti B, Madern D, Ginzburg M, Ginzburg BZ, Giudici-Orticoni MR, Bruschi M, and Zaccai G. Adaptation to extreme environments: macromoleculardynamics in bacteria compared in vivo by neutron scattering. EMBO Rep 5: 66-70, 2006.

93. Todgham AE, Crombie TA, and Hofmann GE. The effect of temperature adaptation on the ubiquitin-proteasome pathway in notothenioid fishes. J Exp Biol 220: 369-378, 2017.

94. Tsigos I, Mavromatis K, Tzanodaskalaki M, Pozidis C, Kokkinidis M, and Bouriotis V. Engineering the properties of a cold active enzyme through rational redesign of the active site. Eur J Biochem 268: 5074-5080, 2001.

95. Verde C, Giordano D, Bellas CM, di Prisco G, and Anesio AM. Polar marine microorganisms and climate change. Adv Microb Physiol 69: 187-215, 2016.

96. Vergara A, Vitagliano L, Merlino A, Sica F, Marino K, Verde C, di Prisco G, and Mazzarella L. An order-disorder transition plays a role in switching off the Root effect in fish hemoglobins. J Biol Chem 285: 32568-32575, 2010.

97. Vergara A, Vitagliano L, Verde C, di Prisco G, and Mazzarella L. Spectroscopic and crystallographic characterization of bis-histidyl adducts in tetrameric hemoglobins. Methods Enzymol 436: 425-444, 2008.

98. Vinogradov S, Hoogewijs D, Bailly X, Arredondo-Peter R, Gough J, Dewilde S, Moens L, and Vanfleteren JR. Three globin lineages belonging to two structural classes in genomes fromthe three kingdoms of life. Proc Natl Acad Sci U S A 102: 11385-11389, 2005.

99. Vinogradov $S$ and Moens L. Diversity of globin function: enzymatic, transport, storage, and sensing. J Biol Chem 283: 8773-8777, 2008.
100. Vinogradov S, Tinajero-Trejo M, Poole RK, and Hoogewijs D. Bacterial and archaeal globins-a revised perspective. Biochim Biophys Acta 1834: 1789-1800, 2013.

101. Vitagliano L, Vergara A, Bonomi G, Merlino A, Verde C, di Prisco G, Howes BD, Smulevich G, and Mazzarella L. Spectroscopic and crystallographic characterization of a tetrameric haemoglobin oxidation reveals structural features of the functional intermediate $\mathrm{R} / \mathrm{T}$ state. $\mathrm{J}$ Am Chem Soc 130: 10527-10535, 2008.

102. WeilandTR, Kundu S, Trent JT III, Hoy JA, and Hargrove MS. Bis-histidyl hexacoordination in hemoglobins facilitates heme reduction kinetics. J Am Chem Soc 126: 11930-11935, 2004.

103. Wittenberg JB, Bolognesi M, Wittenberg BA, and Guertin M. Truncated hemoglobins: a new family of hemoglobins widely distributed in bacteria, unicellular eukaryotes, and plants. J Biol Chem 227: 871-874, 2002.

104. Xie L and Chen Z-N. The activation entropy change in enzymatic reaction catalyzed by isochorismate-pyruvate lyase of Pseudomonas Aeruginosa PchB. 2017. https://arxiv .org/abs/1711.01705 (accessed November 2, 2019).

Address correspondence to: Dr. Cinzia Verde

Institute of Biosciences and BioResources (IBBR)

CNR

Via Pietro Castellino 111

Napoli 80131

Italy

E-mail: c.verde@ibp.cnr.it; cinzia.verde@ibbr.cnr.it

Date of first submission to ARS Central, September 14, 2019; date of acceptance, September 30, 2019.

$$
\begin{aligned}
& \text { Abbreviations Used } \\
2 / 2 \mathrm{Hb} & =\text { two-on-two hemoglobin } \\
2 / 2 \mathrm{HbN} & =\text { two-on-two hemoglobin of group I } \\
2 / 2 \mathrm{HbO} & =\text { two-on-two hemoglobin of group II } \\
5 \mathrm{c} & =\text { penta-coordinate } \\
6 \mathrm{c} & =\text { hexa-coordinate } \\
6 \mathrm{cHS} & =\text { hexa-coordinate high-spin } \\
\kappa & =\text { transmission coefficient } \\
\Delta \mathrm{G}^{*} & =\text { activation free energy } \\
\Delta \mathrm{H}^{*} & =\text { activation enthalpy } \\
\Delta \mathrm{S}^{*} & =\text { activation entropy } \\
\mathrm{BS}-2 / 2 \mathrm{HbO} & =\text { TrHbO of Bacillus subtilis } \\
\mathrm{MDH} & =\text { cytosolic malate dehydrogenase } \\
\mathrm{FHb} & =\text { flavoHb } \\
h & =\text { Planck constant } \\
\mathrm{Hb} & =\text { hemoglobin } \\
\mathrm{ILS} & =\text { implicit ligand sampling } \\
k & =\text { reaction rate } \\
k_{\mathrm{B}} & =\text { Boltzmann constant } \\
\mathrm{k}_{\mathrm{cat}} & =\text { catalytic-rate constant } \\
\mathrm{K}_{\mathrm{m}} & =\text { Michaelis-Menten constant } \\
\mathrm{LS} & =\text { low spin } \\
\mathrm{MD} & =\text { molecular dynamics } \\
M t-2 / 2 \mathrm{HbO} & =\text { TrHbO of M. tuberculosis }
\end{aligned}
$$


Abbreviations Used (Cont.)

$P h-2 / 2 \mathrm{HbO}-0030=$ truncated hemoglobin encoded by PSHAa0030 gene and belonging to Pseudoalteromonas haloplanktis TAC125

$P h-2 / 2 \mathrm{HbO}-2217=$ truncated hemoglobin encoded by PSHAa2217 gene and belonging to $P$. haloplanktis TAC125

$P h \mathrm{TAC} 125=P$. haloplanktis $\mathrm{TAC} 125$
$\mathrm{RMSF}=$ root mean square fluctuations

RNS $=$ reactive nitrogen species

$\mathrm{ROS}=$ reactive oxygen species

$\mathrm{RR}=$ resonance Raman

$\mathrm{T}=$ absolute temperature

$T f-2 / 2 \mathrm{HbO}=\mathrm{TrHbO}$ of Thermobifida fusca

$\mathrm{T}_{\mathrm{m}}=$ thermal denaturation temperature $\mathrm{TrHb}=$ truncated $\mathrm{Hb}$

$\mathrm{TrHbOs}=$ truncated $\mathrm{Hb}$ of group Os $\mathrm{TS}=$ transition-state 